\title{
Systematic Review \\ Mobile Applications for Epilepsy: Where Are We? Where Should We Go? A Systematic Review
}

\author{
Mariana Abreu $1,2, *,+\left(\mathbb{D}\right.$, Ana Sofia Carmo ${ }^{1,2,+}\left(\mathbb{D}\right.$, Ana Franco ${ }^{3}$, Sara Parreira ${ }^{3}$, Beatriz Vidal ${ }^{2}$, Mariana Costa ${ }^{2}$, \\ Ana Rita Peralta ${ }^{3}$ (D) Hugo Plácido da Silva ${ }^{1,2}$, Carla Bentes ${ }^{3}$ (D) and Ana Fred , $^{1,2}$ \\ 1 Instituto de Telecomunicações (IT), 1049-001 Lisbon, Portugal; ana.sofia.carmo@tecnico.ulisboa.pt (A.S.C.); \\ hsilva@lx.it.pt (H.P.d.S.); afred@lx.it.pt (A.F.) \\ 2 Instituto Superior Técnico, Universidade de Lisboa, 1049-001 Lisbon, Portugal; \\ beatriz.vidal@tecnico.ulisboa.pt (B.V.); mariana.r.costa@tecnico.ulisboa.pt (M.C.) \\ 3 Departamento de Neurologia, Centro Hospitalar Universitário Lisboa Norte, EPE, 1649-028 Lisbon, Portugal; \\ ana.c.franco@chln.min-saude.pt (A.F.); sara.parreira@chln.min-saude.pt (S.P.); \\ ana.peralta@chln.min-saude.pt (A.R.P.); carla.bentes@chln.min-saude.pt (C.B.) \\ * Correspondence: mariana.abreu@tecnico.ulisboa.pt \\ + These authors contributed equally to this work.
}

check for updates

Citation: Abreu, M.; Carmo, A.S.;

Franco, A.; Parreira, S.; Vidal, B.;

Costa, M.; Peralta, A.R.; da Silva, H.P.;

Bentes, C.; Fred, A. Mobile

Applications for Epilepsy: Where Are We? Where Should We Go? A

Systematic Review. Signals 2022, 3 ,

40-65. https://doi.org/10.3390/

signals3010005

Academic Editor: Chin-Ling Chen

Received: 7 December 2021

Accepted: 7 January 2022

Published: 3 February 2022

Publisher's Note: MDPI stays neutral with regard to jurisdictional claims in published maps and institutional affiliations.

Copyright: (C) 2022 by the authors. Licensee MDPI, Basel, Switzerland. This article is an open access article distributed under the terms and conditions of the Creative Commons Attribution (CC BY) license (https:// creativecommons.org/licenses/by/ $4.0 /)$.

\begin{abstract}
The development of mobile health for epilepsy has grown in the last years, bringing new applications (apps) to the market and improving already existing ones. In this systematic review, we analyse the scope of mobile apps for seizure detection and epilepsy self-management, with two research questions in mind: what are the characteristics of current solutions and do they meet users' requirements? What should be considered when designing mobile health for epilepsy? We used PRISMA methodology to search within App Store and Google Play Store from February to April of 2021, reaching 55 potential apps. A more thorough analysis regarding particular features was performed on 26 of those apps. The content of these apps was evaluated in five categories, regarding if there was personalisable content; features related to medication management; what aspects of seizure log were present; what type of communication prevailed; and if there was any content related to seizure alarm or seizure action plans. Moreover, the 26 apps were evaluated through using MARS by six raters, including two neurologists. The analysis of MARS categories was performed for the top and bottom apps, to understand the core differences. Overall, the lowest MARS scores were related to engagement and information, which play a big part in long-term use, and previous studies raised the concern of assuring continuous use, especially in younger audiences. With that in mind, we identified conceptual improvement points, which were divided in three main topics: customisation, simplicity and healthcare connection. Moreover, we summarised some ideas to improve m-health apps catered around long-term adherence. We hope this work contributes to a better understanding of the current scope in mobile epilepsy management, endorsing healthcare professionals and developers to provide off-the-shelf solutions that engage patients and allows them to better manage their condition.
\end{abstract}

Keywords: mobile health; systematic review; epilepsy management

\section{Introduction}

Over 50 million people worldwide suffer from epilepsy, being one of the most common neurological diseases, according to the WHO [1]. Epilepsy consists of a predisposition for unprovoked seizures, which are periods of abnormal synchronous neural activity. A seizure results from an excessive electrical discharge in a brain region, from which the outcome ranges from brief absence moments to minute-long generalised convulsions. From these outcomes, the patient is prone to suffer an accident, injury or even sudden unexpected death in epilepsy (SUDEP). Besides the danger weighing upon the seizure, there is also the unpredictability associated with these events. Even though anti-seizure medication (ASM) reduces seizure frequency, $30 \%$ of patients are not responsive to treatment [2]. Thus, the uncertainty of the next seizure event can inhibit epileptic patients from living a regular life. 
Many advances were made globally, in recent years, to reduce the burden of living with epilepsy, from raising awareness to improving overall epilepsy care. Still, there are many unmet needs for patients with epilepsy (PWE), such as misdiagnosis and access to treatment [3], which have been further exacerbated by the COVID-19 pandemic [4,5]. Some of the reasons leading to PWE's unmet needs are lack of information, lack of availability of health services and poor accessibility [6]. The widespread technology could play an essential role in epilepsy care and reduce the burden of epilepsy [4,7].

\subsection{Seizure Diary and Self-Report}

The concept of seizure diary consists of keeping track of seizures on a daily basis. Self-report indicates that this tracking is performed by the patient. Initially, self-report was performed through paper-based seizure diaries, first evolving to web-pages [8], whereas nowadays, we have several electronic solutions available at hand for self-report.

The act of self-report was firstly presented by Albert Bandura in 1977 [9], through the psychological theory of self-efficacy, which stated that active self-management could positively contribute to chronic disease control. In the 1990s, upon the success of selfmanagement towards other chronic diseases (such as diabetes), Dilorio and colleagues [10] proposed that the self-management of epilepsy could enhance seizure control and improve well-being. This was proven by Fraser and coworkers, through a randomised controlled trial in 2015 [11].

Besides the benefit of self-efficacy, if the self-report is associated to the patient-doctor communication, it provides valuable information to health professionals, allowing them to better understand treatment adherence and seizure improvement over time. Moreover, clinical trials of anti-seizure medication (ASM), performed by pharmaceutical companies, also use self-reporting in their studies, which emphasises the importance of accurate seizure tracking.

Blachut and colleagues [12] interviewed more than 100 participants of ASM clinical trials and discussed the issue of under-report: over $40 \%$ of noticed seizures were not reported. Regarding annotation tools, it was mentioned a prevalence of $73.4 \%$ regarding paper-based seizure diaries, when compared to electronic versions, due to ease of use. However, paper diaries were usually filled later on, thereby increasing forgetfulness and memory-associated errors. This study highlighted the role of electronic diaries (e-diaries) in reducing under-report, through the use of daily reminders. However, to accomplish better self-report, this study also recognised the major role of low-complex solutions, emphasizing the need for simple and fast user interaction with e-diaries.

The widespread use of technology in our daily life has brought new possibilities to epilepsy. Recently, Patel et al. [13] published the results of using an e-diary in a randomised, controlled clinical trial, achieving an e-compliance of $83.6 \%$. Through using daily diary reminders, $90 \%$ of seizure events were reported within 1 day after their occurrence. This ediary was provided to patients in a handheld device. Some patients still relied occasionally on paper backup diary entries, with the following reasons stated: lacking availability of the e-diary; forgetting entry into the e-diary; or losing it.

Due to the increasing pervasiveness of smartphones, mobile apps are mostly available in a near range, and easy to access on a daily basis, whenever necessary. Following this line of thought, seizure self-report through a mobile app combines the advantages of ediaries, with being always at hand. Besides seizure reporting, a mobile app could also provide additional features, such as adverting for medicine intake, doctor appointments and keeping track of relevant occurrences. The management of available content should be carefully thought to maintain adherence, by juggling simplicity with engagement.

\subsection{Mobile Health in Epilepsy}

In light of the COVID-19 pandemic, several works have addressed the importance of telemedicine in epilepsy, to ensure the communication between patients and doctors. Even though many interesting solutions have been developed so far, the main communication 
channel reported was telephone calls [14], which despite its ease of use, provides limited interaction and is intensive in human resources.

On another note, the patient-doctor communication is mainly focused on the medical appointment, which can be insufficient to extract conclusions, since the patient might not recall every episode or might have some difficulties in properly describing all relevant information. The follow-up of PWE should be more frequent, but without increasing doctors' overload. In this sense, mobile applications can be an important ally to close the gap between the patients' daily experiences and the doctors' clinical judgement. However, considering the multitude of options available, each with their one purpose and features, an updated systematic evaluation of such tools is missing to provide a clear answer to this topic.

Previous works have conducted systematic reviews of state-of-the-art technology for epilepsy management. Escoffery and colleagues [15] performed an in-depth review of mobile apps for epilepsy self-management, where the apps were evaluated with MARS. This study, published in 2018, was conducted in 2016. In 2020, Zollner and coworkers [16] published a review on clinical decision support systems for epileptology, in which more apps and other solutions are described, but without the MARS evaluation. More recently, Mohammadzadeh and colleagues [17] performed a systematic review of M-health applications used in epilepsy. This study did use MARS; however, the evaluation was performed by a single rater, and only apps from the Google Play store that were available in English were considered.

Considering the rapidly evolving nature of mobile technology [18] and the exponential growth of available apps (with an average number of new app releases per month of more than 70,000 and 30,000 for Google Play and Apple App Store, respectively [19,20]), regular updates on the currently available solutions are crucial. Hence, the present work will provide a review on epilepsy management apps, in light of the most recent technologies and their rigorous evaluation.

Building upon the state of the art, this work also proposes key features that should be present in epilepsy management apps, and what considerations must be taken when envisioning such solutions. The acquired knowledge and thoughts are compiled into a proposal of key aspects to be considered when designing this kind of mobile app, to guide developers into the patients' needs and expectations.

We performed a systematic review following PRISMA methodology [21]. In the methodology section, we start by identifying the research questions (A), the search strategy (B), and the eligibility criteria (C). Herein, we also describe the contents in mobile apps for epilepsy management (D); we conclude with details over the evaluation performed (E) and subsequent analysis (F). The results section is initiated with the PRISMA scheme selection (A), followed by the raters description (B). We performed this analysis starting with content features (C), then the MARS rating assessment (D). In the discussion section, we address the principal findings (A) and the main aspects to include in mobile app development (B), followed by the limitations of our study (C) and comparison with prior work (D). In the conclusion section, we round up the final remarks and main statements disclosed in this review.

\section{Methodology}

This work is focused on epilepsy mobile health catered towards self-management and seizure detection. In chronic diseases, such as epilepsy, patients play an active role in the control and management of their own condition [22]. Self-management includes five processes stated by Grady and colleagues [22]: problem solving, decision making, resource utilization, partnerships with healthcare providers and taking action. Hence, we can consider epilepsy self-management: knowing the details of the disease, ASM intake control or seizure tracking, as examples. Self-management also accounts for the active participation of relatives and caregivers and not only the patients themselves. On the other hand, in seizure detection, patients are mostly passive subjects in the process. Seizure detection 
consists of monitoring data and assessing if a seizure is occurring, without requiring any upfront action from the patients. The inclusion of seizure detection apps in this work is related to their ability to analyse pervasive data unobtrusively, which can empower patients with more knowledge about their condition.

\subsection{Research Questions}

To guide this work, two primary research questions (RQs) were set, as follows:

RQ1: What are the currently available mobile applications designed for epilepsy self-management (SM) and seizure detection (SD)? What are their characteristics? How do they comply with usability and patients' needs?

RQ2: What are the key features to improve user experience of mobile application for epilepsy self-management and seizure detection?

\subsection{Search Strategy}

The search for mobile apps for epilepsy self-management was conducted in both Google Play Store and Apple App Store, encompassing two of the most widely used mobile operating system (OS)_Android and iOS, respectively. This work was performed independently by two reviewers (the authors MA and ASC), who evaluated the suitability of each candidate according to the aforementioned criteria. The keyword used for search purposes was "epilepsy".

Moreover, another search was conducted for the final set of apps, regarding their presence in the literature and use in previous research. For this step, the channels used were the app's website, Google Scholar, ResearchGate, PubMed and IEEE explore. The keywords selected were the app name or related words.

\subsection{Eligibility Criteria}

The mobile apps included in this review were selected according to the following hierarchical criteria: (1) related to epilepsy; (2) specific for epilepsy; and (3) with relevant purpose (allowed to save seizure entries or detect seizures). In this phase, epilepsy apps could be excluded for having other purposes, such as diagnosis, dissemination and education, and emergency details, as examples. All the apps found meeting these criteria were downloaded and included in a first round of analysis, in which general information about the apps was retrieved. Afterwards, three more criteria were assessed: (4) ability to open the app for further interaction (besides login page); and (5) the available languages include EN, ES, PT or FR.

For accurate characterization by our raters, an authentic interaction between the rater and the mobile app is imperative; therefore, all mobile apps whose access was in some way blocked (e.g., access restricted to an institution, external equipment required for full functionality or premium access only) or that were only available in languages other than EN, PT, ES and FR were not further considered in the study.

The last criterion (6) was defined by a neurologist (ARP) by considering which features are imperative in a mobile app for epilepsy self-management and seizure detection, namely, (6) the presence of two core features: seizure log (SL) - the ability to record a seizure event that occurred somewhere in time; and third-party communication (TPC) - the ability to communicate with caregivers and doctors, as for sharing reports or for alerting in case of an emergency. All apps that did not feature both characteristics were not further considered in the study. The presence/absence of these two features indicated whether the app met patients' needs (RQ1) for reasonable self-management.

\subsection{Mobile App Description}

This section describes some of the features that can be found in seizure management and seizure detection apps and categorises them in four groups, which will be hereinafter used to describe and evaluate the eligible mobile applications. 


\subsubsection{Seizure Log}

SL relates to the possibility of registering a new seizure event, either while it is occurring or deferred. It may record event-related information, such as the type, its duration and the time when the event took place, as well as some additional information, such as triggers or post-seizure symptoms, if medication was taken, and the location where it took place.

SL can be presented in a calendar format, as a list, or in any other way visible to the user. One way of visually displaying the information is through statistical plots. Therefore, associated with the SL category, four features were selected as pertaining to this category: SL-1—seizure stats (statistical information related to seizures); SL-2—-seizure-related events stats (statistics on triggers, related symptoms and so on); SL-3-medication stats (statistics on the relation of medical adherence with seizure events); and SL-4-other events log (whether it is possible to record other events that could be interesting to keep track of as well, such as the period cycle, sleep cycle, mood, among others).

\subsubsection{Medication}

Another common tool in self-management mobile apps is associated with treatment. Since medication plays an important role in seizure control, we evaluate how it is managed within the app through four features: M-1-type and dosage (whether it is possible to log new drugs, and if so, if the type and dosage is asked inside this feature); $\mathrm{M}-2$ - schedule (if it is possible to associate alarms and/or notification reminders); M-3-history (whether past medications are saved or if only current medications are displayed); M-4-side effects (if there is an entry for side effects or possibly medication-related symptoms).

\subsubsection{Third-Party Communication}

TPC is assessed in two different areas: one is related to sharing seizure logs and related events, whereas the other pertains to the activation of some action during emergencies, through alerting family members or other designated people. Within this topic we assess the communication channels deployed: Phone (whether the app allows to call a designated number), E-mail (if information is sent by e-mail), App2App (if the caregiver or doctor is expected to have a related app to access the patient's details), Web (if there is a web platform that is managed by the doctor and displays relevant information), Instant msg. apps (if it is possible to share reports or other information through third-party communication apps, such as WhatsApp, Facebook Messenger, among others). Besides communication channels, in TPC we also assess if a summary of logs is created and shareable, hereinafter referred to as Report export.

\subsubsection{During Seizure}

The last category evaluates if there is an area related to ongoing seizures, which could be video/audio recording seizure events in real-time, providing best-practices/guidelines on how to proceed during an ongoing seizure, or alerting someone for assistance.

Since communication was already assessed in the previous category, herein we evaluated the presence of four other features: DS-1 Alarm Button (a button to be pressed to access during seizure procedures or record events); DS-2 Seizure Procedures (whether it is displayed information on the best actions to assist a seizure); DS-3 GPS Tracking (if GPS location is possible to save associated with the event or to send to someone); DS-4 Video \& Audio (which includes the automatic recording of video and audio when the alarm button is pressed, or when additional buttons are pressed).

\subsection{Mobile App Evaluation}

To evaluate the mobile apps, firstly we analysed which was the prevalence of the aforementioned features, and related statistics. Moreover, we recurred to an usability scale, to evaluate user experience and related details, in a quantitative score. 
The mobile app rating scale (MARS) [23] was created with the purpose of providing a multidimensional, standard and objective way of evaluating and comparing mobile health applications (MHA), deviating from the highly subjective and often uninformative star rating. This scale was developed by pooling several previously used website and app assessment criteria and classifying them into categories and subcategories (each with scale items and descriptors), thus creating a comprehensive scale, with a rationale for each criteria.

As such, MARS evaluates four objective quality categories (engagement, functionality, aesthetics and information quality), each with sub-items as presented in Table 1. Each MARS item is classified using a 5-point scale (1-inadequate, 2-poor, 3-acceptable, 4-good, and 5-excellent), and the final MARS score is given both as the individual mean scores of the objective categories and as the overall mean (overall mean app quality total score). Stoyanov et al. [23] also proposed an additional subjective quality category. Due to its subjective nature, this category is purposefully considered as separate to the objective scoring; hence, it is left out from the overall mean app quality score and is analysed individually.

For the purpose of this work, three sub-items belonging to the information category were not addressed, namely, the accuracy of the app description, credibility and evidence base.

Table 1. MARS objective quality categories (item) and respective sub-categories (sub-items). Adapted from Stoyanov and colleagues [23].

\begin{tabular}{ccccc}
\hline Item & Engagement & Functionality & Aesthetics & Information \\
\hline \multirow{4}{*}{ Sub-items } & Entertainment & Performance & Layout & Accuracy of app description \\
& Interest & Ease of use & Graphics & Goals \\
& Customisation & Navigation & Visual appeal & Quality of information \\
& Interactivity & Gestural design & & Quantity of information \\
& Target group & & & Credibility \\
& & & & Evidence base \\
\hline
\end{tabular}

As recommended when using MARS, all sub-items were discussed and agreed upon between the raters, prior to rating. Raters were expected to use the app for some time and test its features and interactive widgets. Besides MARS scoring, the raters were also asked to describe the app using a single word, through an open field, which was not mandatory to answer.

\subsection{Statistical Analysis on MARS Scores}

Since our analysis through MARS is scored by more than one rater, we selected some statistical analyses to help understand and validate the results. This type of analysis was also conducted in the review of Escoffery and colleagues [15], with relevant purpose in the results section. To evaluate intraclass correlation, we used ICC2k [24]. This coefficient evaluates the level of agreement between raters, which varies between 0 and 1 . This value is also presented with the $95 \%$ confidence interval (CI) - the closer to one, the greater the agreement and, therefore, the intraclass correlation.

Besides ICC2k, the MARS overall score of each app was the arithmetic mean over the scores of the items given by each rater. The subjective part of MARS was analysed separately.

\section{Results}

This section comprises four subsections. Section 3.1 introduces the outcomes of our search and eligibility criteria. Section 3.2 describes the raters who installed the apps and surveyed their features and user experience. Section 3.3 contains the analysis of the features previously described in Section 2.4. Finally, Section 3.4 presents the MARS scores: overall score for all selected apps, and category scores for the top 5 apps of each OS. 


\subsection{Mobile App Selection}

As displayed in Figure 1, 375 apps were identified in our review, including 53 duplicates. From the remaining 322 apps, 146 were excluded for not being related to epilepsy. Then, from the 176 apps, 60 were excluded for not being specific to epilepsy. Finally, the epilepsy apps were only included if their purpose was self-management of epilepsy in humans or seizure detection, reaching a total of 55 eligible apps.

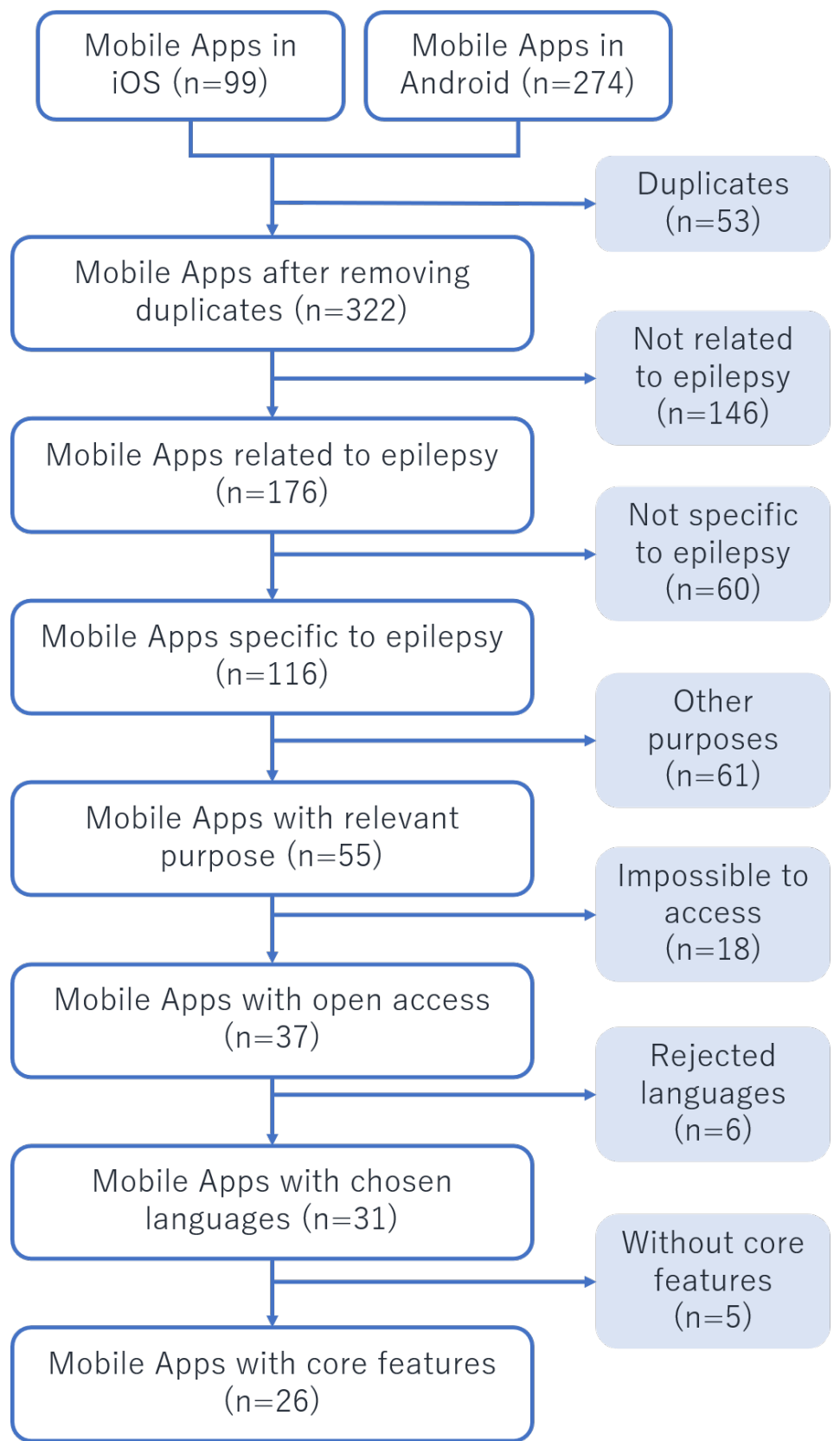

Figure 1. PRISMA scheme for the selection of the relevant mobile apps, according to hierarchical criteria: (1) related to epilepsy; (2) specific for epilepsy; (3) with relevant purpose; (4) with open access; (5) with understandable language; and (6) with most desirable features. The apps that fulfil the criteria (1,2 and 3) were elected for the first phase of analysis, where criteria $(4,5$ and 6$)$ were analysed. For the deeper analysis, it was only considered the apps that fulfil all criteria $(n=26)$.

This set of 55 mobile apps was reviewed and described according to the OS, available languages, purpose and accessibility, along with the two key features, i.e., if they provided SL and TPC. The full description of all apps can be consulted in Table A1 in Appendix A. 
This information was retrieved from the description in the App Store or Play Store, the associated website (if any) and basic first impressions.

In order to perform the in-depth analysis of the apps, a second round of exclusion was accomplished. As such, from the set of 55 apps, 18 were excluded for not allowing complete access to the features; thereupon, 6 more apps were excluded for not being available in EN, PT, ES or FR, and 5 others were excluded for not providing the core features (i.e., SL and TPC).

From the second round of exclusion, 26 mobile apps complied with the criteria (as demonstrated in Table A1). As such, these mobile apps were further analysed in order to provide a more comprehensive description of what a user can expect. This description provides a set of more in-depth features, organised in five categories described in Section 2.4: (a) seizure log (SL), (b) medication (Med), (c) third-party communication (TPC) (d) available options during seizures (DS) and (e) personalisable content. The full description can be consulted in Tables A2 and A3 in Appendix B.

\subsection{Raters}

For the purpose of this analysis, six subjects performed the rating of a varying number of mobile apps, according to their mobile phone's OS. Table 2 shows the descriptions of the subjects that participated in this study. Note that, even though none of the subjects represent the target audience of epilepsy apps, all had some prior knowledge of the disease and the limitations/characteristics that this group may have, and this knowledge was transposed to the classification (e.g., when addressing categories related to the fitness of some feature to the target group). Namely, two raters were neurologists specialised in epilepsy.

Table 2. Description of subjects that participated in the study as raters. Discriminated age group and OS.

\begin{tabular}{lccc}
\hline ID & Age Range & OS & \# Rated Apps \\
\hline R1 & & iOS & 16 \\
R2 & {$[18,30]$} & iOS & 15 \\
R3 & Android & 18 \\
R4 & & Android & 18 \\
R5 & & iOS & 13 \\
R6 & & Android & 10 \\
\hline
\end{tabular}

\subsection{Analysis of Features Provided}

As required, every app that was considered eligible for the in-depth feature analysis provided both SL and TPC features. However, within the five categories analysed in Appendix B, the remaining three categories (i.e., medication, available options during seizures and personalisable content) were considered optional. As such, it is interesting to see their prevalence across apps. Figure 2 shows the ratio of mobile apps that provide each of the three optional categories of features, according to the apps' purpose.

According to the bar plot, the difference between apps with different purposes is quite evident. For example, while DS features appear to be essential in apps whose purpose is seizure detection (SD), the same cannot be said regarding self-management (SM) apps, as less than half of these apps provide this category of features. One can argue that SD solutions are less about the interaction with the patient and more towards autonomous recording. This diminishes the need for other features that are perhaps more associated to disease management. The same reasoning can be observed for the other two categories (medication and personalised content), which provide features that improve disease management and usability, thus being more frequent in SM apps.

Interestingly, medication appears to be a priority within SM mobile apps, since around $80 \%$ of the analysed apps provided this category of features. 


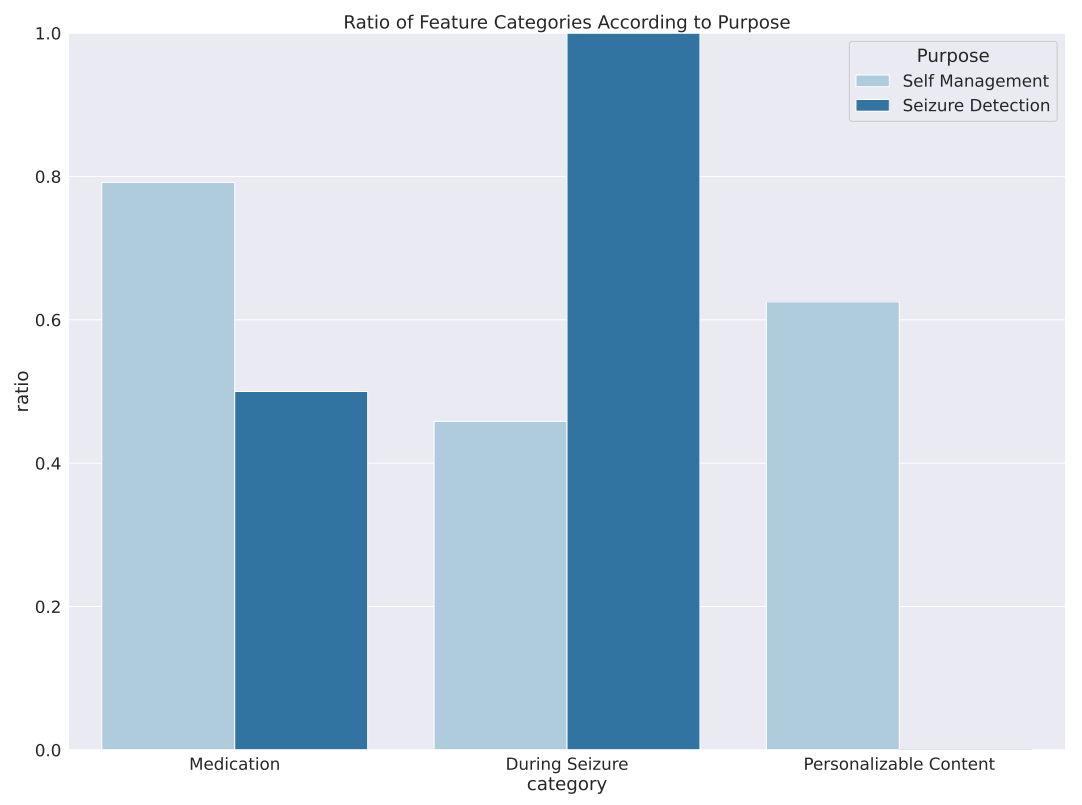

Figure 2. Ratio of apps that provide features related to medication, during seizure and personalisable content. All seizure detection apps contain during seizure, whilst the most prevalent category in self-management apps is medication.

Each of the feature categories (except personalisable content) is further subdivided into features, as illustrated in Figure 3. This provides an overview of the most (and less) common features within each category. On its own, this highlights what the developers/medical entities involved in the development of the apps perceive as necessary features in epilepsy mobile apps (accounting for development efforts they entail). A very clear example is the medication category: while every app within the apps that has the medication category provides the monitoring of the type and dosage of the current medications, the history of previous pharmacotherapies (and possible reasons for abandoning them) is rather overlooked by these entities.

As it was previously stated, all the apps considered have some type of TPC. In Figure 3, we encounter a variety of communication channels, phone, e-mail, App2App, web and instant message apps, where the most common is the e-mail, and the least common is App2App. App2App implies creating another version of the app directed to the caregiver or doctor, which is not accessible in a computer, hindering the collection of information within the context of a doctor's appointment. To pass relevant information in a concise way, $70 \%$ of apps allow Report Export. This feature is very relevant for doctors for summarising the patient's information regarding a particular time period.

\subsection{MARS Ratings}

The process of app rating through MARS can contribute to a better understanding of the the user experience and how the apps differ from one another. Even though we shared with the raters the apps' purpose, the evaluation through MARS was performed with free interpretation from the MARS questionnaire proposed in [23].

Most applications were developed for a single OS, whereas only 9 out of 26 exist for both iOS and Android. This condition precludes raters to evaluate all 26 applications. To evaluate the inter-rater agreement between scores, we analysed the intra-class correlation coefficient within the different OS. The inter-rater agreements were reliable for both Android scores (ICC2k score of 0.83 and 95\% confidence interval between 0.5 and 0.95 ) and iOS scores (ICC2k $=0.85$ with $95 \% \mathrm{CI}=[0.62,0.95])$. Moreover, for the 7 apps that were possible to rate by 5 or more raters, the inter-rater agreement was ICC $2 \mathrm{k}=0.79$ with $95 \% \mathrm{CI}=[0.37,0.95]$. This value of agreement indicates a consistent reasoning between our raters. Nonetheless, 
the following analyses were performed separately according to the OS, since most apps were only rated for one of the OS. Moreover, it is relevant to acknowledge that even for apps that exist in both OS, the actual design and overall experience may differ, which further justifies this decision.

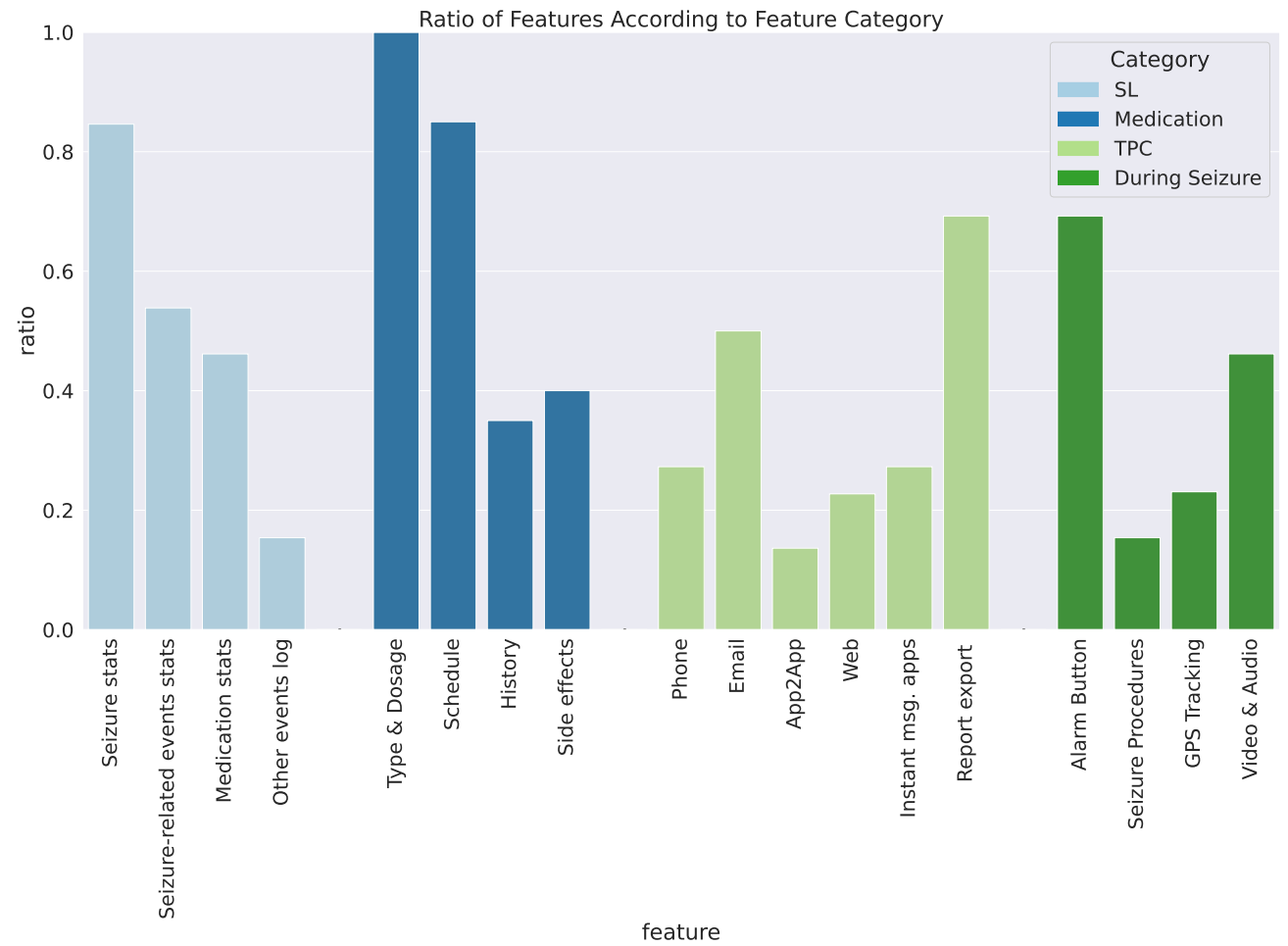

Figure 3. Ratio of apps that provide a particular feature. Note: the ratios are computed within the number of apps that contain the corresponding category of features.

In Table A4 (in the Appendix C), it is disclosed for all selected apps: the number of raters, the average score of each MARS category and overall score. Since these averages were calculated joining both OS, their values may slightly differ from the results discussed in this section.

In Figure 4, the average MARS rating is displayed for all rated apps. The left plot corresponds to apps rated for iOS, whereas the right plot contains the apps rated in the Android system. Considering the top five scores of each plot, it is possible to identify two common apps: helpilepsy, and Epilepsy Journal. With the exception of Epilepsy Connect and E-Epilepsy Inclusion, iOS scores present low deviation between the 3 raters $(0.13 \pm 0.06)$. Conversely, in Android, the scoring was more diverse, since deviation was (0.24 \pm 0.12$)$, even after removing the large deviations of My Epilepsy and Epilepsy-Seizures Diary. Nonetheless, these values are concordant with ICC2k inter-rater agreements. Moreover, overall scoring in iOS system ranged from 2.9 to 4.5, being consistently higher than the Android system, whose values range from 2.1 to 4.1 .

On the right side of Figure 4, the second best app, EpApp was only rated by R3, since the login was not successful for the other raters. Therefore, we will not take in account this app further on, since it can be less representative. The same thought was followed in the left side of the plot, where the app +Control Diario Epilepsia was the best for rater R1 and R2, but it was inaccessible for rater R6. Even though the two raters have a good agreement, the fact that the rater R6 could not login, associated to the last update being in 2016 (last check for updates was in July of 2021) led to the decision of leaving it out of further analysis in iOS. 

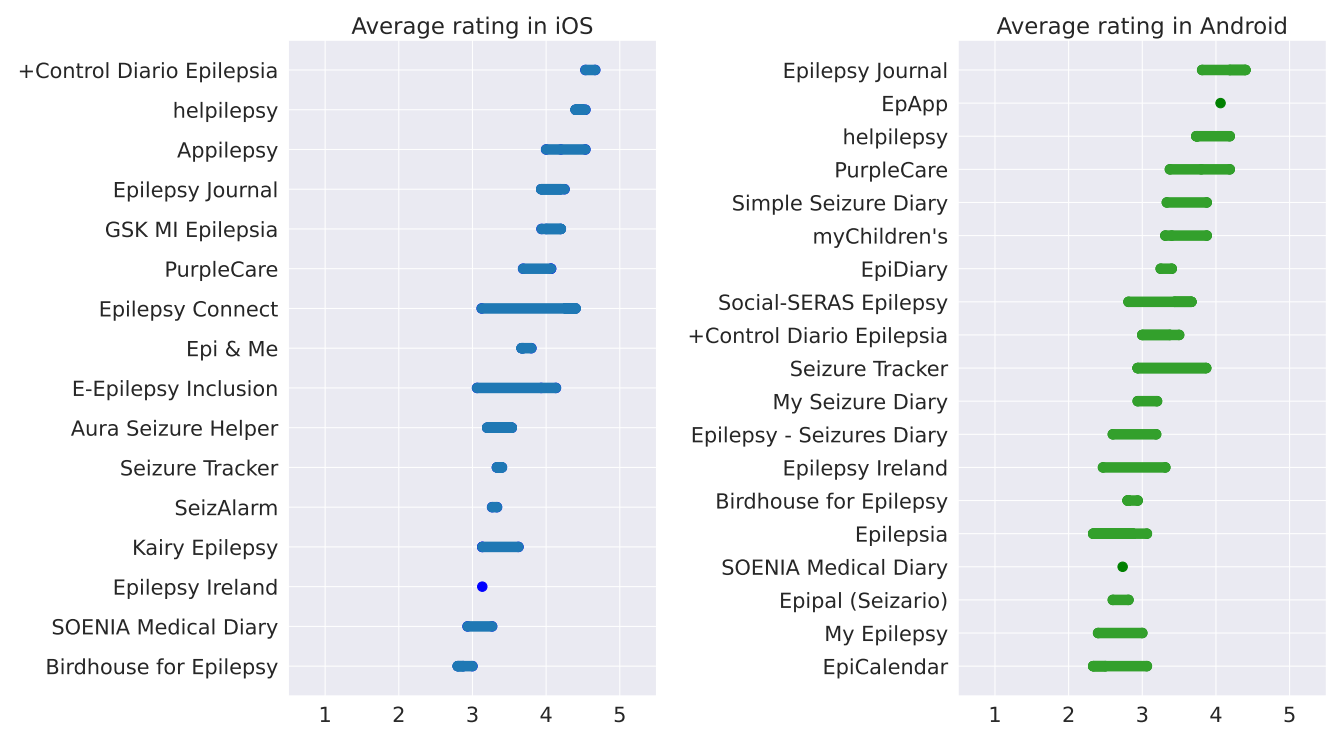

Figure 4. Overall rating of each app. The left side plot contains apps evaluated in the iOS system, whereas the right side corresponds to apps evaluated within the Android system. On the left, the scores vary between 2.9 and 4.5, while on the right, the scores range from 2.1 to 4.1 .

To proceed to the analysis of each MARS category, we only considered the top five (top 5) apps of each OS, over the scores of the five bottom (bottom 5) apps. In this manner, we can perform our judgement regarding the effect each category plays in the overall scoring. This analysis is presented in Figures 5 and 6 for the iOS and Android, respectively.

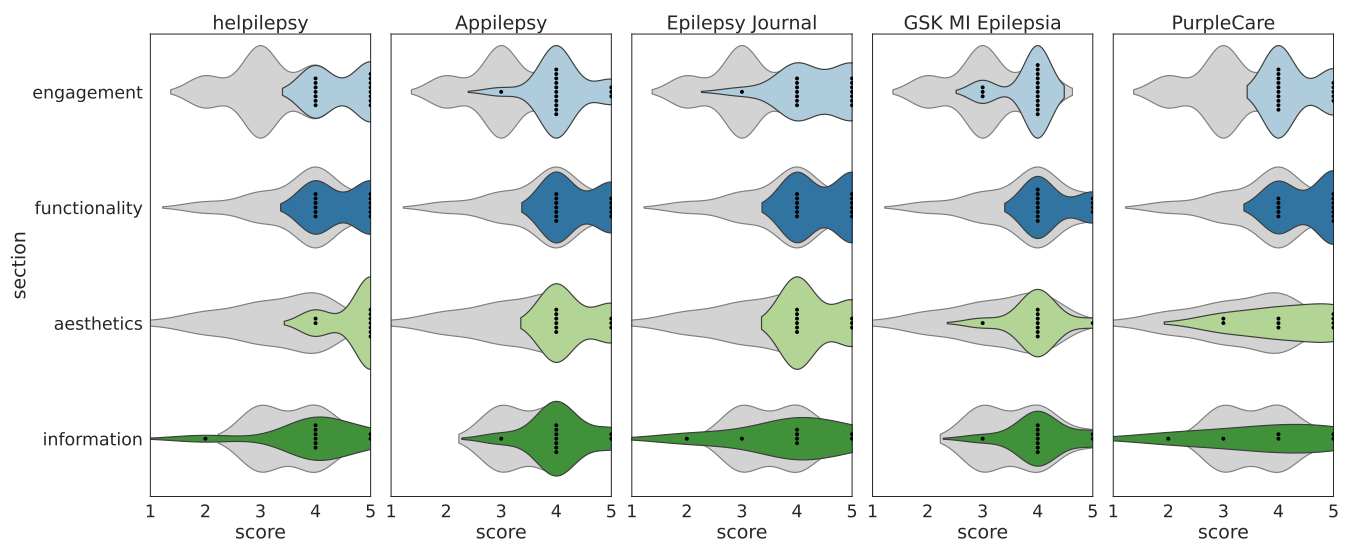

Figure 5. Section scores for top 5 iOS apps.

In helpilepsy, the homepage contains statistics and notifications. The notifications are related to treatment intake and mood and sleep, and the daily reminder is optional. This app has an appealing design and interesting functionalities, whereas its downside is the nonexistence of education about epilepsy, and there is no calendar view, only a daily view of past events. Hence, the high score in aesthetics, and low score in information. Appilepsy's homepage shows statistics in a simple colour scheme of purple, white and blue. At the bottom, it contains a menu to jump to other pages, such as SL and medication. In the SL page, there is a send icon to send seizure log list to any e-mail contact. The upfront statistics engages the user to dive into seizure events and trigger frequency.

Since the bottom 5 also present distributions around four for aesthetics and functionality, these two categories were highly scored in overall, meaning that these bottom applications also presented some interest to the raters, which is justified for the bottom 5 apps mean score being $3.19 \pm 0.17$. By observing the engagement section, we see a distri- 
bution around 3 for the bottom applications, whereas the top 5 have distributions between 4 and 5 . Thus, this category could be playing a bigger part in the overall user experience, leading to better ratings.
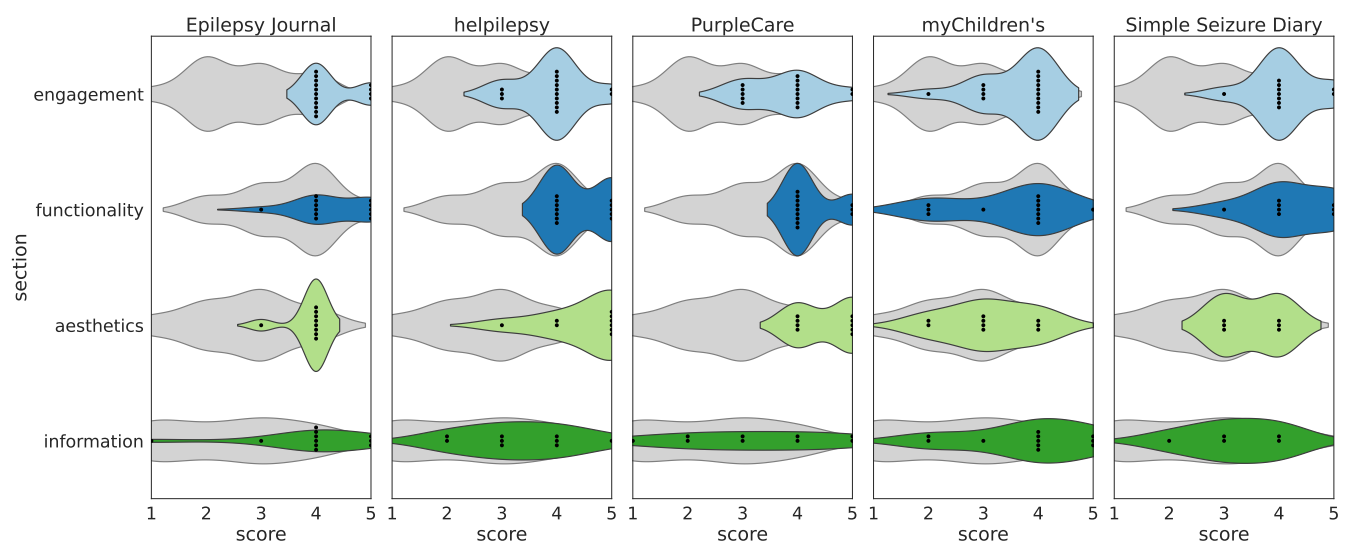

Figure 6. Section scores for top 5 Android apps.

Shown in Figure 6, we performed the same analysis to the apps evaluated through Android. Epilepsy Journal scored high in both systems. This is the only app that provides a diverse set of languages to choose from; hence, it was tested in Portuguese. Even though the design is not very appealing, with an add on the top of the page, it presents an easy flow, since all important functionalities are in the home page or side menu button. It contains statistics, an alarm button that is also for seizure logging, and a personalised report that is shareable by e-mail. This app receives constant updates (last update was on 10 July 2021) and has over 50 thousand downloads in Google Play, and more than 600 reviews with a mean review score of 4.0. Since helpilepsy was already mentioned, we will move on to the third best Android app - PurpleCare. This app contains very interesting features, such as video recording and the addition of exams and laboratory tests. It also has a good design, a web platform for health professionals and regular updates (the last being on 5 July 2021). However, the flow is not very clear, where more than one button needs to be pressed to perform a basic action (for example, to insert a new seizure). In the Play Store, this app has only +50 downloads and the overall rating is still unknown.

For the top 5 Android apps, engagement and functionality are consistently higher than the bottom applications. For the bottom apps of Figure 6, engagement distribution is around 2; however, functionality is shaped similarly to iOS. In terms of information, the bottom apps distribution spreads evenly throughout the scale. When analysing these observations, we conclude that all applications, android and iOS, have considerably good functionality and similar score in information (between top and bottom), thus what mostly contributes to a better rating is based on engagement and slightly better aesthetics.

The last items on the MARS scale approached whether the raters would recommend the app to other people or how many times would they use the app in 12 months. These scores were consistent with the rest of the evaluation, where helpilepsy got 5 in iOS for all raters, and Epilepsy Journal got 4 in Android.

In the section $\mathrm{E}$ of methodology, we mention that the raters had the option to describe the apps in a single word. This was performed by raters R5 and R6, who are neurologists, specialised in epilepsy. When asked to describe each app in one word, the android bottom apps got "minimal" and "basic", and Kairy Epilepsy was described as "too much stuff". The apps Seizure Tracker and Social-SERAS Epilepsy that lay in the middle of the Android scale were described as "overwhelming", whereas, the top apps of Android were described with "practical", "comprehensive", "interesting" and "fun". The top iOS apps were described as "interesting", and the availability of other languages besides English was praised. 


\section{Discussion}

This section comprises four subsections. Section 4.1 presents the main findings of our systematic review. Section 4.2 expresses the thoughts on prior work. Section 4.3 explains the key concepts to be applied in the development of self-management apps for epilepsy. Lastly, Section 4.4 addresses the limitations of this work.

\subsection{Main Findings}

In this review, we analysed the available options of mobile applications to help manage epilepsy. From our search, 55 applications serve the purpose of seizure detection or epilepsy self-management, and these were compiled into Table A1 (in the Appendix A) where we show their accessibility type, available languages and core features. With this analysis, we encountered 18 apps with closed access, 6 applications with unknown languages for the raters, and 5 applications without one of the core features: third-party communication and seizure log. Thus, it brought our total to 26 eligible apps to be tested under the MARS rating and to be evaluated according to deeper features. Besides SL and TPC, the most common feature in epilepsy self-management applications was medication and it was present in $79 \%$ of applications. Within the medication category, $100 \%$ of the apps presented type and dosage, which was inserted by the patient in a medication log. More than $80 \%$ provided a schedule for treatment intake, $40 \%$ allowed to record side effects and $35 \%$ saved past medications in a history section. For seizure detection applications, the most common feature was during seizures, with a prevalence of $100 \%$. In the whole set of apps, the most prevalent feature in DS was the alarm button, while the remaining DS features, video and audio, GPS tracking and seizure procedures are in $48 \%, 23 \%$ and $17 \%$ of the apps, respectively.

Through MARS, we have an assessment of four categories, which are general to health-related applications. In our analysis, the best scores were not necessarily the apps with more interesting features, but they provided a good trade-off between simplicity and "added value".

One important note in m-health is the credibility and the evidence base. From our pool of apps, few were described in prior studies, and connection to hospitals or health practitioners is not disclosed. SeizureTracker is the app with broader scientific range. Over the years, SeizureTracker collected a patient-centred database, which has been used in multiple studies [25-27]. Epipal (Seizario), a seizure detection app, was described and tested by Helmy and colleagues [28,29]. SOENIA Medical Diary is described as a CE-marked medical device, with clinical studies performed in Tampere University Hospital [30]; however, the reports are not publicly available. PurpleCare [31] won awards in recent years for digital health innovation. This app was mentioned in a letter to the editor [32], where the author also collaborated with clinical inputs to the app development. Nonetheless, the positive outputs are only displayed as personal opinions of a few people. This is also the case of helpilepsy [33]. Appilepsy was also created with the feedback of doctors and caregivers, and it was mentioned on a news article of the Dravet Syndrome Foundation [34]. From this pool of apps, only EpApp was described and tested in a previous study [35], with positive outcomes for epilepsy self-management in young people with epilepsy.

\subsection{Thoughts on Prior Work}

Previous reviews, which evaluated apps through MARS, also reached low values of engagement and information [15,17]. These reviews were conducted in fall 2017 and between February 2018 and April 2019, respectively. Since then, there has been little to no improvement concerning these categories, which may play an important role in long-term adherence. These reviews also stated the lack of cohort studies and randomised trials associated to the apps. Since then, one app was developed in such way (Brain4U) [36], where its effectiveness was also tested with end-users [37]. However, this app was only available in Korean, and thus was excluded in the last selection of our review. Nonetheless, Brain $4 U$ can be an example for how $\mathrm{m}$-health systems should be deployed in the future. This 
clinical validation increases confidence over the use of the app, which could be helpful to keep engagement. Since these apps are designed for epileptic patients, doctors and patients should be involved in the app's design from day one. Alzamanan and colleagues [38] noted the significant difference between the number of people with epilepsy and the number of users in epilepsy self-management apps. In this work, it was proposed three ideas for closing the gap between the target audience and these apps. Another issue stated in previous studies is the target being mostly an adult audience [39]. EpApp was the only app we found that was developed closely with adolescents [35]. Le Marne and colleagues [35] concluded that EpApp's use improved epilepsy knowledge and medication management. This highlights the importance of such apps in the lives of young people with epilepsy, hence the need for broadening the target audience to include younger people. In our review, EpApp was in the top of the MARS scale (Figure 4); however, this app was only possible to test by one rater before becoming inaccessible. Regarding young people with epilepsy, current applications are not designed for engaging continuous use [40]. DozièresPuyravel [39] and colleagues surveyed adolescents with epilepsy and their parents. While parents were more focused on accurate seizure management and emergency information, adolescents expected daily life related contents and tools for anti-seizure medication (ASM) compliance. This article emphasises the need for customization and tailoring for each adolescent's needs, in order to increase adherence over time. Another work, by Thompson and colleagues [40] interviewed patients and relatives of patients with epilepsy, concerning the design of a mobile health system towards adolescents and young adults. Participants described wanting an easy and fast access to safety procedures upon seizure, through audio or video output. Moreover, concerning the use of current applications, they mentioned alarm fatigue and the "burden of having to manually record multiple entries" [40]. These two concerns are related to our assessment in MARS since seizure procedures are part of information, and alarm fatigue reduces engagement over time. Thus, new ways of engaging are necessary to improve adherence over time. Rahim and coworkers [41] suggested the use of gamification to improve medication adherence in epilepsy through several ideas stated, such as being associated to a social network or having a virtual reward system (this idea was also prompted by one adolescent interviewed in the previous study [40]).

On a different note, recent studies are dedicated to forecasting seizure risk by using seizure's cyclic behaviour, sleep rhythms and weather data, as examples [42,43]. Hence, self-management apps could be an important ally for seizure prediction, in collecting relevant data for algorithm development and in displaying results to patients', who, in turn, could reply with feedback. This engagement loop could benefit both patients and research, bringing an additional layer of purpose to such m-health solutions.

\subsection{Key Concepts of an Epilepsy Self-Management App}

When designing a new app for health self-management, some considerations should be taken to meet end-users' needs. Hence, we recommend to follow a user-centred model, such as the one proposed by Schnall and colleagues [44]. In order to establish standard data elements amongst m-health epilepsy solutions, a consortium of key stakeholders was formed in 2016, and Goldenholz and colleagues published their conclusions [45]. Here, one can find an appendix with different items and the associated entries and the respective level of requirement within an epilepsy m-health system. This appendix can be a starting point for developers to know the standard terminology and preferred items to be included. The thorough analysis of the 26 applications, combined with the opinion of health professionals and prior work of peers, help to identify key elements for an epilepsy self-management mobile application. First of all, it is important to provide the key features of SL and TPC for an effective epilepsy self-management. Medication is also an important feature that will increase adherence to the app since it is key to self-management. Moreover, it is important to offer other things, such as graphics and calendar views of one's entries, and also to provide information about the disease to increase literacy on epilepsy. Additional details are also interesting, such as other logs (sleep, mood or even doctor appointments), camera 
access during seizure, and import of medical exams. However, we should have in mind that less can be more, where too many features could increase confusion. In our MARS evaluation, some apps with many of these features were not well rated (such as Epi $\mathcal{E} M e$ and Seizure Tracker). Hence, a good app is a trade-off between necessary features and their display, design-wise.

\subsubsection{Customisation}

To achieve all these interesting features without overload, customisation is the solution. Customisation can be considered in the following implementations: choice of features; creation of seizure templates; time and periodicity of notifications; adaptive and dynamic content and self-representation or virtual companion. In addition, language is also very relevant. The app should provide the language of their patients, besides English. Since foreign patients entered the app, the developers should care about broadening their language spectrum since a less-known language can lead to miscomprehension and, consequently, loss of interest.

\subsubsection{Simplicity}

Simplicity is also important to account for a broader target audience. To increase simplicity, the app could provide short-range access to all features; audio to record new logs (instead of manual entries); easy access to app's tutorial; and immediate login without password/constant registration.

Since the smartphone possesses so many alternative ways to interact, the app does not need to be only based on tapping and manual entries. We could use gesture recognition, voice controls, and movement commands to reduce the burden and monotony of simple logging. On the other hand, the app should be always open, while still having protection on sensible information. It is exhausting to keep having to login or remember passwords in a daily-use app. Other ways could be creating a unique ID that does not require manual registration.

\subsubsection{Healthcare Connection}

The app should be a facilitator and a bridge for patient-doctor communication. Some of the information, such as medication and seizure details, are better known by the doctor than by the patient; hence, the doctor could tailor these features to the patients' specifics. Moreover, patients would have an additional interest to insert seizures if they are to show the diary to the doctor. For this, it is also important to have a report created whenever necessary to summarise the events occurred in the designated time period. Moreover, there could be an area to place questions or important notes, to help remember them in the following appointment.

\subsection{Limitations}

The work developed in this study was performed in Portugal Lisbon; therefore, some applications mentioned in other papers were not present in our Google Play Store and App Store, such as EPSY. Moreover, due to language barriers, some available apps were not possible to evaluate, such as Thailand's Epilepsy Diary 3, still. These are mentioned in Table A1.

Concerning MARS evaluation, it was performed between May and August of 2021; hence, we only rated one up to two versions of each app. For this reason, some apps that were initially functional gave login errors in the last ratings, for example, Control Diario Epilepsia. As a disclaimer, the opposite might have happened as well, where we discarded some apps in the previous step for login issues, and those can be functioning properly at the moment. To address this concern, we chose to show in Table A1 the accessibility, language and SL and TPC categories. 
On another note, the small range of versions rated of each app, and their continuous improvement over time, could not play a truthful picture of the current version of the app. Our thorough comparison is not intended to be a static evaluation of the best apps, but to understand which direction is more appropriate towards user experience and epilepsy self-management and well-being.

\section{Conclusions}

This thorough comparison serves the purpose of understanding what is relevant to consider in an epilepsy management app, how can it stand out and what should it have to offer, besides the basics, to become more appealing to the end-user. We reviewed current apps available on the market, concerning the presence of features in the following categories: seizure log, third-party communication, medication and during seizure. These apps were also evaluated by six raters using MARS. From the analysis of previous work, patients with epilepsy and families stated their opinion regarding epilepsy mobile management and proposed some ideas to improve current solutions. We compiled those thoughts with our review and opinions in a reflection of the key concepts for epilepsy mobile management. Moreover, we identified three important points to be incorporated in future designs: customisation, simplicity and healthcare connection. The proposed ideas were considered for an epilepsy management system; however, they are easily translated to other mobile health applications. We believe our conclusions will help to improve overall patient experience, which, in turn, will raise adherence to treatment and continuous longterm management.

Author Contributions: Authors M.A. and A.S.C. contributed in the systematic review and app selection, analysis and writing of the paper. Authors M.A., A.S.C., A.F. (Ana Franco), S.P., B.V. and M.C. performed the MARS rating. Authors A.R.P., H.P.d.S. and A.F. (Ana Fred) supervised the systematic search and selection criteria. Authors H.P.d.S., C.B., A.F. (Ana Franco) and A.F. (Ana Fred) reviewed the paper. All authors have read and agreed to the published version of the manuscript.

Funding: This work was partially funded by Fundação para a Ciencia e Tecnologia (FCT) under the grant 2021.08297.BD, and under the project PCIF/SSO/0163/2019 "SafeFire", by the FCT/Ministério da Ciência, Tecnologia e Ensino Superior (MCTES) through national funds and when applicable co-funded by EU funds under the project UIDB/50008/2020, by the IT-Instituto de Telecomunicações under grant $\mathrm{BI} / \mathrm{N}^{\circ} 16-16 / 03 / 2021$, and with the support of Centro Hospitalar Universitário Lisboa Norte, EPE, under the project "PreEpiSeizures".

Institutional Review Board Statement: Not applicable.

Informed Consent Statement: Not applicable.

Data Availability Statement: The data collected in this work is available upon request to the correspondence author.

Conflicts of Interest: The authors declare no conflict of interest.

\section{Abbreviations}

The following abbreviations are used in this manuscript:

$\begin{array}{ll}\text { AFo } & \text { Ana Franco } \\ \text { AFd } & \text { Ana Fred } \\ \text { AR } & \text { Arabic } \\ \text { ARP } & \text { Ana Rita Peralta } \\ \text { ASC } & \text { Ana Sofia Carmo } \\ \text { ASM } & \text { Anti-seizure Medication } \\ \text { BV } & \text { Beatriz Vidal } \\ \text { CanE } & \text { Canadian English } \\ \text { CanF } & \text { Canadian French } \\ \text { CB } & \text { Carla Bentes }\end{array}$




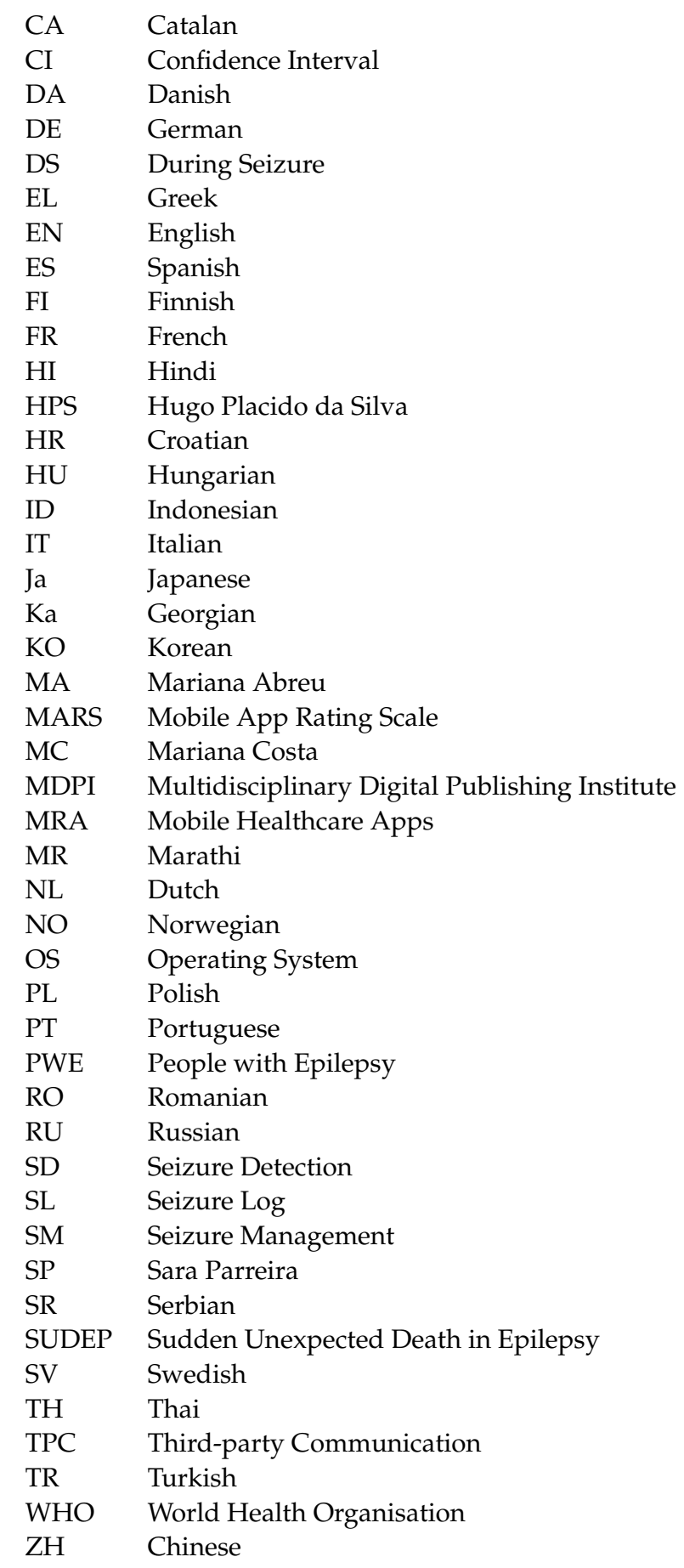




\section{Appendix A. Overall App Description}

Table A1. Mobile applications for epilepsy management and detection. SL is the seizure log, and TPC is third-party communication. The black dot indicates whether the app was selected for the final pool of 26.

\begin{tabular}{|c|c|c|c|c|c|c|c|}
\hline & App Name & Platform & Languages & Purpose & SL & TPC & Access \\
\hline • & $\begin{array}{l}\text { +Control Diario Epilepsia } \\
\text { (Fundacion Carlos Slim) }\end{array}$ & Android and iOS & ES & SM & $\checkmark$ & $\checkmark$ & Free \\
\hline & $\begin{array}{l}\text { Alert for Embrace Watch } \\
\text { \& Mate for Embrace Watch } \\
\text { (Empatica) }\end{array}$ & Android and iOS & EN & SD & $\checkmark$ & $\checkmark$ & $\begin{array}{l}\text { Premium and } \\
\text { Needs } \\
\text { equipment }\end{array}$ \\
\hline & $\begin{array}{l}\text { Anfallskalender } \\
\text { (FLYT IT AS) }\end{array}$ & iOS & NB & SM & $\checkmark$ & - & Free \\
\hline$\bullet$ & $\begin{array}{c}\text { Appilepsy } \\
\text { (Appilepsy LLC) }\end{array}$ & iOS & $\mathrm{EN}$ & SM & $\checkmark$ & $\checkmark$ & Free \\
\hline$\bullet$ & $\begin{array}{c}\text { Aura Seizure Helper } \\
\text { (Stevhen) }\end{array}$ & iOS & EN, ID & SM & $v$ & $\checkmark$ & Free \\
\hline \multirow[t]{4}{*}{$\bullet$} & $\begin{array}{l}\text { Birdhouse for Epilepsy } \\
\text { (Birdhouse LLC) }\end{array}$ & Android and iOS & $\mathrm{EN}$ & SM & $V$ & $\checkmark$ & $\begin{array}{l}\text { Free and } \\
\text { Premium }\end{array}$ \\
\hline & $\begin{array}{c}\text { Bleuberi } \\
\text { (H2L2 Technology Ltd) }\end{array}$ & iOS & $\mathrm{EN}$ & SM & & - & 2-week trial \\
\hline & $\begin{array}{c}\text { Brain4U } \\
\text { (MedToPublic) }\end{array}$ & Android and iOS & $\mathrm{KO}$ & SM & & $\checkmark$ & Free \\
\hline & $\begin{array}{l}\text { Brio - Heart Rate Monitor } \\
\text { (Candlhat Studios) }\end{array}$ & Android and iOS & EN & SD & & - & $\begin{array}{l}\text { Needs } \\
\text { equipment }\end{array}$ \\
\hline \multirow[t]{2}{*}{$\bullet$} & $\begin{array}{c}\text { E-Epilepsy Inclusion } \\
\text { (The Hong Kong Society } \\
\text { of Rehabilitation) }\end{array}$ & Android ${ }^{1}$ and iOS & $\mathrm{ZH}, \mathrm{EN}$ & SM & & & Free \\
\hline & $\begin{array}{c}\text { ELFy } \\
\text { (ELFy Apps Limited) }\end{array}$ & Android and iOS & EN & SM & - & $\checkmark$ & Free \\
\hline$\bullet$ & $\begin{array}{c}\text { EpApp } \\
\text { (Sidney Children's } \\
\text { Hospitals Network) }\end{array}$ & Android and iOS & $\mathrm{EN}$ & $\mathrm{SM}$ & & $\checkmark$ & Free \\
\hline \multirow[t]{3}{*}{ • } & $\begin{array}{c}\text { Epi \& Me } \\
\text { (HandMe) }\end{array}$ & iOS & EN, FR & SM & $\checkmark$ & $\checkmark$ & Free \\
\hline & $\begin{array}{c}\text { EpiAnfald } \\
\text { (Filadelfia DK) }\end{array}$ & $\mathrm{iOS}$ & $\mathrm{DA}, \mathrm{EN}$ & SM & $\checkmark$ & - & Closed \\
\hline & $\begin{array}{c}\text { EPIC } \\
\text { (Epilepsy Care) }\end{array}$ & Android & $\mathrm{EN}$ & SD & & $\checkmark$ & $\begin{array}{l}\text { Failed to } \\
\text { access }\end{array}$ \\
\hline$\bullet$ & $\begin{array}{l}\text { EpiCalendar } \\
\text { (MedyCal) }\end{array}$ & Android & PT & SM & & $\checkmark$ & $\begin{array}{c}\text { Free \& } \\
\text { Premium }\end{array}$ \\
\hline \multirow[t]{2}{*}{$\bullet$} & $\begin{array}{c}\text { EpiDiary } \\
\text { (Irody Inc.) }\end{array}$ & Android and iOS & $\mathrm{EN}$ & SM & $\checkmark$ & $\checkmark$ & Free \\
\hline & $\begin{array}{l}\text { Epihunter Companion } \\
\text { and Epihunter Core } \\
\text { (Epihunter nv) }\end{array}$ & Android and iOS & EN, NL & SD & $\checkmark$ & $\checkmark$ & $\begin{array}{l}\text { Premium and } \\
\text { Needs } \\
\text { equipment }\end{array}$ \\
\hline
\end{tabular}


Table A1. Cont.

\begin{tabular}{|c|c|c|c|c|c|c|c|}
\hline & App Name & Platform & Languages & Purpose & SL & TPC & Access \\
\hline \multirow[t]{2}{*}{ • } & $\begin{array}{c}\text { Epilepsia } \\
\text { (Maleny Abrego) }\end{array}$ & Android & ES & SM & $\checkmark$ & $\checkmark$ & Free \\
\hline & $\begin{array}{c}\text { Epilepsia Mexico } \\
\text { (Ivan Gonzalez Cortes) }\end{array}$ & iOS & ES & SM & $\checkmark$ & $\checkmark$ & Closed \\
\hline \multirow[t]{2}{*}{ • } & $\begin{array}{c}\text { Epilepsy Seizures Diary } \\
\text { (MedTests) }\end{array}$ & Android & EN & SM & $\checkmark$ & $\checkmark$ & Free \\
\hline & $\begin{array}{c}\text { Epilepsy } \\
\text { (Tan Hui Jan) }\end{array}$ & $\mathrm{iOS}$ & EN & SM & $\checkmark$ & - & Free \\
\hline \multirow[t]{4}{*}{ - } & $\begin{array}{l}\text { Epilepsy Connect } \\
\text { (Epilepsy France) }\end{array}$ & iOS & FR & SM & . & $\checkmark$ & Free \\
\hline & $\begin{array}{c}\text { Epilepsy Diary } 3 \\
\text { (Crystal Software Group: } \\
\text { CSG mobile team) }\end{array}$ & Android & $\mathrm{TH}$ & SM & & $\checkmark$ & Free \\
\hline & $\begin{array}{c}\text { Epilepsy Diary } 5 \\
\text { (Crystal Software Group: } \\
\text { CSG mobile team) }\end{array}$ & Android & $\mathrm{TH}$ & $\mathrm{SM}$ & & $\checkmark$ & Free \\
\hline & $\begin{array}{c}\text { Epilepsy Foundation } \\
\text { (Chowgule Mediconsult } \\
\text { Private LTD) }\end{array}$ & Android and iOS & $\begin{array}{l}\text { EN, HI, } \\
\text { MR }\end{array}$ & SD & & $\checkmark$ & $\begin{array}{l}\text { Failed to } \\
\text { access }\end{array}$ \\
\hline - & $\begin{array}{l}\text { Epilepsy Ireland } \\
\text { (Epilepsy Ireland) }\end{array}$ & Android and iOS & EN & SM & $\checkmark$ & $\checkmark$ & Free \\
\hline \multirow[t]{2}{*}{$\bullet$} & $\begin{array}{c}\text { Epilepsy Journal } \\
\text { (Olly Tree Applications) }\end{array}$ & Android and iOS & $\begin{array}{c}\text { PT, DE, } \\
\text { ZH, HR, } \\
\text { ES, FR, } \\
\text { KA, EL, } \\
\text { HI, NL, } \\
\text { EN, IT, JA, } \\
\text { NB, PL, } \\
\text { RO, RU, } \\
\text { SV, SR }\end{array}$ & $\mathrm{SM}$ & & $\checkmark$ & Free \\
\hline & $\begin{array}{l}\text { Epistemic App } \\
\text { (Epistemic) }\end{array}$ & Android & EN, PT & SM & $\checkmark$ & $\checkmark$ & $\begin{array}{l}\text { Failed to } \\
\text { access }\end{array}$ \\
\hline \multirow[t]{2}{*}{ - } & $\begin{array}{c}\text { GSK MI Epilepsia } \\
\text { (Pharmaconsult, SA) }\end{array}$ & iOS & ES & SM & $\checkmark$ & $\checkmark$ & Free \\
\hline & $\begin{array}{l}\text { Heart Buddy } \\
\text { (Sean Pedley) }\end{array}$ & iOS & EN & SD & - & $\checkmark$ & $\begin{array}{c}\text { Needs } \\
\text { equipment }\end{array}$ \\
\hline \multirow[t]{2}{*}{ • } & $\begin{array}{c}\text { Helpilepsy } \\
\text { (Epione BVBA) }\end{array}$ & Android and iOS & $\begin{array}{l}\text { FR, DE, } \\
\text { NL, EN, } \\
\text { DA, ES, } \\
\text { CANE, } \\
\text { CANF, } \\
\text { HU, IT }\end{array}$ & SM & $\checkmark$ & $\checkmark$ & Free \\
\hline & $\begin{array}{c}\text { Inspyre App } \\
\text { (Smart Monitor) }\end{array}$ & Android & $\mathrm{EN}$ & SD & $\checkmark$ & $\checkmark$ & $\begin{array}{l}\text { Premium and } \\
\text { Needs } \\
\text { equipment }\end{array}$ \\
\hline \multirow[t]{2}{*}{$\bullet$} & $\begin{array}{l}\text { Kairy Epilepsy } \\
\text { (Kairy Limited) }\end{array}$ & $\mathrm{iOS}$ & EN & SM & $\checkmark$ & $\checkmark$ & $\begin{array}{l}\text { Free and } \\
\text { Premium }\end{array}$ \\
\hline & $\begin{array}{c}\text { My Epilepsy } \\
\text { (Catalyst Hub Apps) }\end{array}$ & Android & $\mathrm{AR}, \mathrm{EN}$ & SM & $\checkmark$ & - & Free \\
\hline
\end{tabular}


Table A1. Cont.

\begin{tabular}{|c|c|c|c|c|c|c|c|}
\hline & App Name & Platform & Languages & Purpose & SL & TPC & Access \\
\hline & $\begin{array}{c}\text { My Epilepsy Record } \\
\text { (ESH Solutions Limited) }\end{array}$ & Android and iOS & EN & SM & $\checkmark$ & $\checkmark$ & Closed \\
\hline & $\begin{array}{c}\text { My Epistatus } \\
\text { (Veriton Pharma) }\end{array}$ & Android & EN & SM & $\checkmark$ & $\checkmark$ & Closed \\
\hline$\bullet$ & $\begin{array}{c}\text { My Seizure Diary } \\
\text { (Epilepsy Foundation) }\end{array}$ & Android and iOS & EN & SM & $\checkmark$ & $\checkmark$ & Free \\
\hline \multirow[t]{2}{*}{$\bullet$} & $\begin{array}{c}\text { myChildren's } \\
\text { (Nationwide Children's } \\
\text { Hospital) }\end{array}$ & Android & EN & SM & & $\checkmark$ & Free \\
\hline & $\begin{array}{l}\text { OpenSeizureDetector and } \\
\text { Garmin Connect App } \\
\text { (OpenSeizureDetector) }\end{array}$ & Android & EN, FR, IT & SD & & $\checkmark$ & $\begin{array}{l}\text { Needs } \\
\text { equipment }\end{array}$ \\
\hline \multirow[t]{3}{*}{ • } & $\begin{array}{c}\text { PurpleCare } \\
\text { (DHYGEE SA) }\end{array}$ & Android and iOS & EN, IT, FR & SM & $\checkmark$ & $\checkmark$ & Free \\
\hline & $\begin{array}{c}\text { Sami3 Sleep } \\
\text { Activity Monitor } \\
\text { (HiPass Design LLC) }\end{array}$ & iOs & $\mathrm{EN}$ & SD & & $\checkmark$ & $\begin{array}{c}\text { Needs } \\
\text { equipment }\end{array}$ \\
\hline & $\begin{array}{c}\text { Seer } \\
\text { (Seer Medical) }\end{array}$ & Android and iOS & EN, DE & SM & & - & Free \\
\hline$\bullet$ & $\begin{array}{c}\text { SeizAlarm } \\
\text { (SeizAlarm LLC) }\end{array}$ & $\mathrm{iOS}$ & EN & SD & $\checkmark$ & $\checkmark$ & 2-week trial \\
\hline \multirow[t]{4}{*}{ - } & $\begin{array}{c}\text { Seizario (Epipal) } \\
\text { (HealthAppy Tech) }\end{array}$ & Android & EN & SD & & $\checkmark$ & Free \\
\hline & $\begin{array}{c}\text { Seizure Alert } \\
\text { (My Medic Watch) }\end{array}$ & Android & EN, FR & $\mathrm{SD}$ & & $\checkmark$ & $\begin{array}{l}\text { 30-day trial } \\
\text { and Needs } \\
\text { equipment }\end{array}$ \\
\hline & $\begin{array}{l}\text { Seizure Counter } \\
\text { (SJAPPER AS) }\end{array}$ & iOS & EN & SD & $\checkmark$ & - & Free \\
\hline & $\begin{array}{c}\text { Seizure Cycle } \\
\text { (Sheikh Zayed Institute) }\end{array}$ & Android and iOS & EN? & SM & $\checkmark$ & $\checkmark$ & Closed \\
\hline \multirow[t]{2}{*}{$\bullet$} & $\begin{array}{c}\text { Seizure Tracker/ } \\
\text { Seizure Log } \\
\text { (Seizure Tracker LLC) }\end{array}$ & Android \& iOS & $\mathrm{EN}$ & SM & $\checkmark$ & $\checkmark$ & Free \\
\hline & $\begin{array}{l}\text { SeizureSync Epilepsy Log } \\
\text { (doc.ai) }\end{array}$ & iOS & EN & SD & & $\checkmark$ & $\begin{array}{l}\text { Failed to } \\
\text { access }\end{array}$ \\
\hline$\bullet$ & $\begin{array}{l}\text { Simple Seizure Diary } \\
\text { (Luke Berry) }\end{array}$ & Android & EN & SM & $\checkmark$ & $\checkmark$ & Free \\
\hline$\bullet$ & $\begin{array}{l}\text { Social-SERAS Epilepsy } \\
\text { (mjn-neuro) }\end{array}$ & Android & $\begin{array}{l}\text { CA, EN, } \\
\text { ES }\end{array}$ & SM & & $\checkmark$ & Free \\
\hline \multirow[t]{2}{*}{$\bullet$} & $\begin{array}{l}\text { SOENIA Medical Diary } \\
\text { (BrainCare Oy) }\end{array}$ & Android and iOS & $\begin{array}{l}\text { DE, EN, } \\
\text { FI, SV }\end{array}$ & SM & $\checkmark$ & $\checkmark$ & Free \\
\hline & $\begin{array}{c}\text { Yeditepe EpilepsiSiz } \\
\text { (G Boson) }\end{array}$ & Android and iOS & TR & SM & $\checkmark$ & $\checkmark$ & Free \\
\hline
\end{tabular}




\section{Appendix B. In-Depth Features}

Table A2. In-depth features related to seizure log (SL) and medication (Med). Epilepsy mobile applications for self-management and seizure detection (only remaining candidates, as selected in Table A1).

\begin{tabular}{|c|c|c|c|c|c|c|c|}
\hline Name & $\begin{array}{c}\text { Seizure } \\
\text { Cycle (SL) }\end{array}$ & $\begin{array}{l}\text { Resolution } \\
\quad \text { (SL) }\end{array}$ & Other Logs (SL) & $\begin{array}{l}\text { Type and } \\
\text { Dosage } \\
\text { (Med) }\end{array}$ & $\begin{array}{l}\text { Schedule } \\
\text { (Med) }\end{array}$ & $\begin{array}{l}\text { History } \\
\text { (Med) }\end{array}$ & $\begin{array}{l}\text { Side } \\
\text { Effects } \\
\text { (Med) }\end{array}$ \\
\hline $\begin{array}{l}\text { +Control Diario Epilepsia } \\
\text { (Fundacion Carlos Slim) }\end{array}$ & - & Monthly & Emotion log & $\checkmark$ & $\checkmark$ & - & - \\
\hline $\begin{array}{c}\text { Appilepsy } \\
\text { (Appilepsy LLC) }\end{array}$ & $\checkmark$ & Yearly & $\begin{array}{l}\text { Trigger log on } \\
\text { seizure log }\end{array}$ & $\checkmark$ & $\checkmark$ & - & - \\
\hline $\begin{array}{c}\text { Aura Seizure Helper } \\
\text { (Stevhen) }\end{array}$ & - & Monthly & $\begin{array}{l}\text { Post-seizure } \\
\text { questionnaire }\end{array}$ & - & - & - & - \\
\hline $\begin{array}{l}\text { Birdhouse for Epilepsy } \\
\text { (Birdhouse LLC) }\end{array}$ & Premium & Monthly & $\begin{array}{l}\text { Triggers, sleep } \\
\text { and food }\end{array}$ & $\checkmark$ & Premium & $\checkmark$ & $\checkmark$ \\
\hline $\begin{array}{l}\text { E-Epilepsy Inclusion } \\
\text { (The Hong Kong Society } \\
\text { of Rehabilitation) }\end{array}$ & $\checkmark$ & $\begin{array}{l}\text { Weekly, } \\
\text { Monthly }\end{array}$ & - & $\checkmark$ & & $\checkmark$ & $\checkmark$ \\
\hline $\begin{array}{c}\text { EpApp } \\
\text { (Sidney Children's } \\
\text { Hospitals Network) }\end{array}$ & $\checkmark$ & Daily & $\begin{array}{l}\text { Trigger log on } \\
\text { seizure log }\end{array}$ & & & $\checkmark$ & - \\
\hline $\begin{array}{l}\text { Epi \& Me } \\
\text { (HandMe) }\end{array}$ & $\checkmark$ & List view & $\begin{array}{l}\text { Humour and } \\
\text { energy }\end{array}$ & & $\checkmark$ & $\checkmark$ & $\checkmark$ \\
\hline $\begin{array}{l}\text { EpiCalendar } \\
\text { (MedyCal) }\end{array}$ & - & Daily & Menstrual log & Premium & - & - & - \\
\hline $\begin{array}{l}\text { EpiDiary } \\
\text { (Irody Inc.) }\end{array}$ & $\begin{array}{l}\text { Only on } \\
\text { Website }\end{array}$ & Weekly & $\begin{array}{l}\text { Sleep and } \\
\text { menstrual log }\end{array}$ & & $\checkmark$ & $\begin{array}{l}\text { Only on } \\
\text { website }\end{array}$ & $\checkmark$ \\
\hline $\begin{array}{c}\text { Epilepsia } \\
\text { (Maleny Abrego) }\end{array}$ & - & Daily & $\begin{array}{l}\text { Open-box on } \\
\text { seizure log }\end{array}$ & $\checkmark$ & $\checkmark$ & - & - \\
\hline $\begin{array}{l}\text { Epilepsy Seizures Diary } \\
\text { (MedTests) }\end{array}$ & - & Daily & $\begin{array}{l}\text { Post-seizure } \\
\text { questionnaire and } \\
\text { symptom log }\end{array}$ & $\checkmark$ & - & - & - \\
\hline $\begin{array}{l}\text { Epilepsy Connect } \\
\text { (Epilepsy France) }\end{array}$ & - & Monthly & $\begin{array}{l}\text { Post-seizure } \\
\text { questionnaire }\end{array}$ & $\checkmark$ & - & $\checkmark$ & - \\
\hline $\begin{array}{l}\text { Epilepsy Ireland } \\
\text { (Epilepsy Ireland) }\end{array}$ & $\checkmark$ & Monthly, Daily & $\begin{array}{l}\text { Post-seizure } \\
\text { questionnaire }\end{array}$ & $\checkmark$ & $\checkmark$ & - & - \\
\hline $\begin{array}{c}\text { Epilepsy Journal } \\
\text { (Olly Tree Applications) }\end{array}$ & $\checkmark$ & Monthly, Daily & $\begin{array}{l}\text { Trigger log on } \\
\text { seizure log }\end{array}$ & $\checkmark$ & $\checkmark$ & $\checkmark$ & - \\
\hline $\begin{array}{c}\text { GSK MI Epilepsia } \\
\text { (Pharmaconsult, SA) }\end{array}$ & - & Monthly & $\begin{array}{l}\text { Post-seizure } \\
\text { questionnaire }\end{array}$ & $\checkmark$ & $\checkmark$ & - & - \\
\hline $\begin{array}{c}\text { Helpilepsy } \\
\text { (Epione BVBA) }\end{array}$ & - & $\begin{array}{c}\text { Yearly, } \\
\text { Monthly, } \\
\text { Weekly, Daily }\end{array}$ & $\begin{array}{c}\text { Post-seizure } \\
\text { questionnaire \& } \\
\text { sleep \& mood log }\end{array}$ & $\checkmark$ & $\checkmark$ & - & $\checkmark$ \\
\hline $\begin{array}{l}\text { Kairy Epilepsy } \\
\text { (Kairy Limited) }\end{array}$ & Premium & Weekly & $\begin{array}{l}\text { Logs for several } \\
\text { features }^{\text {a }}\end{array}$ & $\checkmark$ & $\checkmark$ & $\checkmark$ & $\checkmark$ \\
\hline
\end{tabular}


Table A2. Cont.

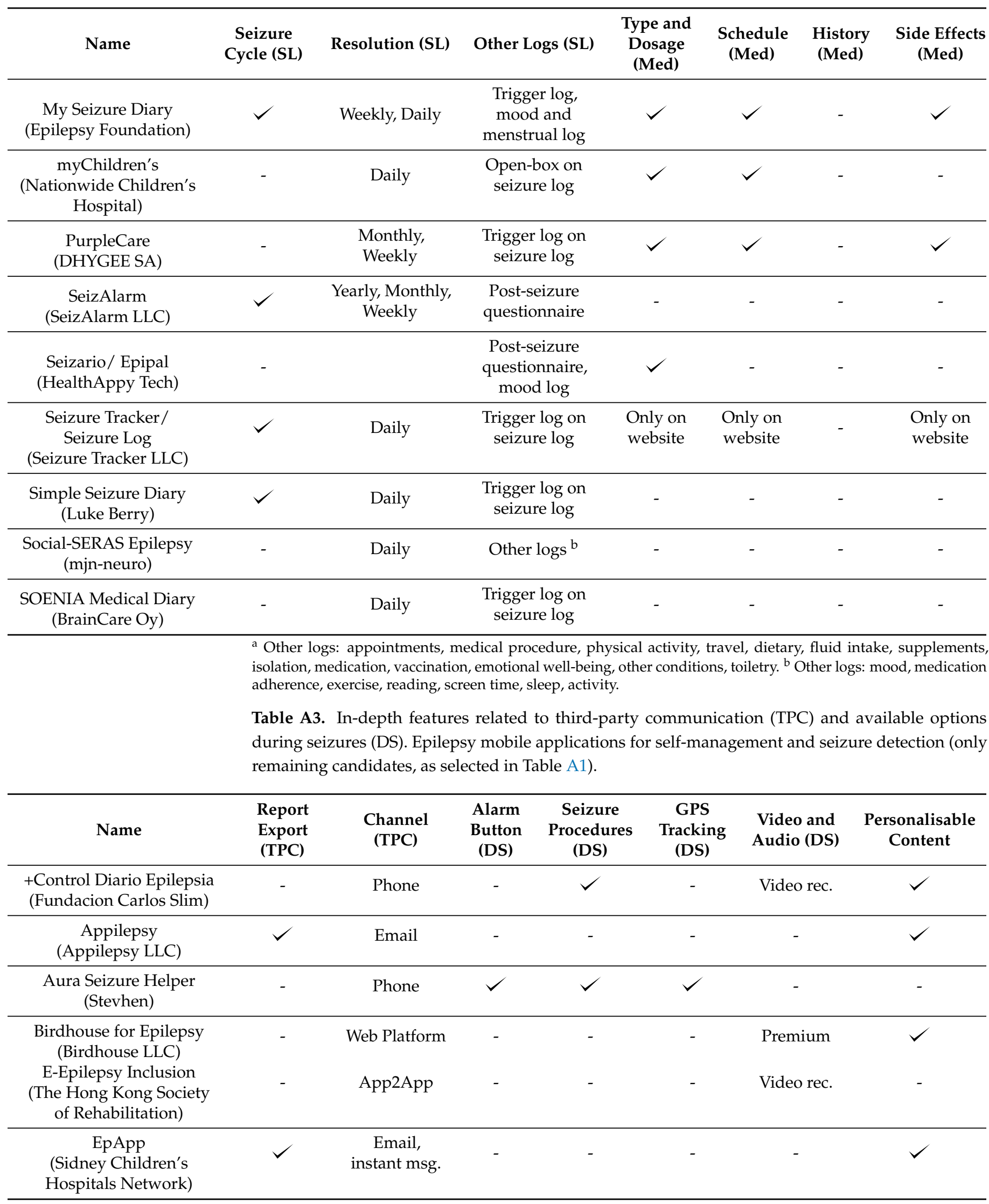


Table A3. Cont.

\begin{tabular}{|c|c|c|c|c|c|c|c|}
\hline Name & $\begin{array}{l}\text { Report } \\
\text { Export } \\
\text { (TPC) }\end{array}$ & $\begin{array}{l}\text { Channel } \\
\text { (TPC) }\end{array}$ & $\begin{array}{l}\text { Alarm } \\
\text { Button } \\
\text { (DS) }\end{array}$ & $\begin{array}{c}\text { Seizure } \\
\text { Procedures } \\
\text { (DS) }\end{array}$ & $\begin{array}{l}\text { GPS } \\
\text { Tracking } \\
\text { (DS) }\end{array}$ & $\begin{array}{l}\text { Video and } \\
\text { Audio (DS) }\end{array}$ & $\begin{array}{l}\text { Personalisable } \\
\text { Content }\end{array}$ \\
\hline $\begin{array}{l}\text { Epi \& Me } \\
\text { (HandMe) }\end{array}$ & $\checkmark$ & Email & - & - & - & - & $\checkmark$ \\
\hline $\begin{array}{l}\text { EpiCalendar } \\
\text { (MedyCal) }\end{array}$ & $\checkmark$ & - & - & - & - & - & - \\
\hline $\begin{array}{l}\text { EpiDiary } \\
\text { (Irody Inc.) }\end{array}$ & $\checkmark$ & Web platform & $\checkmark$ & - & - & - & $\checkmark$ \\
\hline $\begin{array}{c}\text { Epilepsia } \\
\text { (Maleny Abrego) }\end{array}$ & - & Phone & $\checkmark$ & - & $\checkmark$ & - & - \\
\hline $\begin{array}{c}\text { Epilepsy Seizures Diary } \\
\text { (MedTests) }\end{array}$ & $\checkmark$ & $\begin{array}{c}\text { Email, } \\
\text { instant msg. }\end{array}$ & - & - & - & - & - \\
\hline $\begin{array}{l}\text { Epilepsy Connect } \\
\text { (Epilepsy France) }\end{array}$ & $\checkmark$ & - & - & - & - & - & - \\
\hline $\begin{array}{l}\text { Epilepsy Ireland } \\
\text { (Epilepsy Ireland) }\end{array}$ & $\checkmark$ & Email & - & - & - & Video rec. & $\checkmark$ \\
\hline $\begin{array}{c}\text { Epilepsy Journal } \\
\text { (Olly Tree Applications) }\end{array}$ & $\checkmark$ & $\begin{array}{c}\text { Email, } \\
\text { instant msg. }\end{array}$ & $\checkmark$ & - & $\begin{array}{c}\text { Add } \\
\text { location } \\
\text { manually }\end{array}$ & - & - \\
\hline $\begin{array}{l}\text { GSK MI Epilepsia } \\
\text { (Pharmaconsult, SA) }\end{array}$ & $\checkmark$ & $\begin{array}{l}\text { Email, } \\
\text { instant msg. }\end{array}$ & - & - & - & - & - \\
\hline $\begin{array}{c}\text { Helpilepsy } \\
\text { (Epione BVBA) }\end{array}$ & - & Email & - & - & - & Video rec. & - \\
\hline $\begin{array}{l}\text { Kairy Epilepsy } \\
\text { (Kairy Limited) }\end{array}$ & Premium & Premium & - & - & - & - & - \\
\hline $\begin{array}{c}\text { My Seizure Diary } \\
\text { (Epilepsy Foundation) }\end{array}$ & - & App2App & - & - & - & - & $\checkmark$ \\
\hline $\begin{array}{c}\text { myChildren's } \\
\text { (Nationwide Children's } \\
\text { Hospital) }\end{array}$ & $\checkmark$ & $\begin{array}{c}\text { Email, } \\
\text { instant msg. }\end{array}$ & - & $\checkmark$ & - & - & - \\
\hline $\begin{array}{c}\text { PurpleCare } \\
\text { (DHYGEE SA) }\end{array}$ & $\checkmark$ & Web platform & - & - & - & Video rec. & - \\
\hline $\begin{array}{c}\text { SeizAlarm } \\
\text { (SeizAlarm LLC) }\end{array}$ & $\checkmark$ & Email, phone & $\checkmark$ & - & $\checkmark$ & - & - \\
\hline $\begin{array}{c}\text { Seizario/ Epipal } \\
\text { (HealthAppy Tech) }\end{array}$ & - & Phone & $\checkmark$ & - & - & - & - \\
\hline $\begin{array}{c}\text { Seizure Tracker/ } \\
\text { Seizure Log } \\
\text { (Seizure Tracker LLC) }\end{array}$ & $\begin{array}{l}\text { Only on } \\
\text { Website }\end{array}$ & Web platform & $\checkmark$ & - & - & $\begin{array}{l}\text { Video and } \\
\text { audio rec. }\end{array}$ & - \\
\hline $\begin{array}{l}\text { Simple Seizure Diary } \\
\text { (Luke Berry) }\end{array}$ & $\checkmark$ & $\begin{array}{c}\text { Email, } \\
\text { instant msg. }\end{array}$ & $\checkmark$ & - & - & - & $\checkmark$ \\
\hline $\begin{array}{l}\text { Social-SERAS Epilepsy } \\
\text { (mjn-neuro) }\end{array}$ & $\checkmark$ & - & - & - & - & - & $\checkmark$ \\
\hline $\begin{array}{l}\text { SOENIA Medical Diary } \\
\text { (BrainCare Oy) }\end{array}$ & - & Web platform & - & - & $\begin{array}{c}\text { Add } \\
\text { location } \\
\text { manually }\end{array}$ & - & $\checkmark$ \\
\hline
\end{tabular}




\section{Appendix C. MARS Evaluation}

Table A4. Epilepsy applications evaluated with MARS.

\begin{tabular}{|c|c|c|c|c|c|c|}
\hline Name & N Raters & Engagement & Functionality & Aesthetics & Information & Overall \\
\hline $\begin{array}{l}\text { +Control Diario Epilepsia } \\
\text { (Fundacion Carlos Slim) }\end{array}$ & 5 & 3.7 & 4.2 & 3.7 & 4.0 & 3.8 \\
\hline $\begin{array}{c}\text { Appilepsy } \\
\text { (Appilepsy LLC) }\end{array}$ & 3 & 4.1 & 4.4 & 4.3 & 4.1 & 4.2 \\
\hline $\begin{array}{c}\text { Aura Seizure Helper } \\
\text { (Stevhen) }\end{array}$ & 3 & 3.5 & 4.4 & 3.9 & 4.7 & 4.2 \\
\hline $\begin{array}{l}\text { Birdhouse for Epilepsy } \\
\quad \text { (Birdhouse LLC) }\end{array}$ & 6 & 3.0 & 2.9 & 3.2 & 2.7 & 3.0 \\
\hline $\begin{array}{c}\text { E-Epilepsy Inclusion } \\
\text { (The Hong Kong Society of Rehabilitation) }\end{array}$ & 3 & 3.7 & 4.1 & 3.4 & 3.5 & 3.6 \\
\hline $\begin{array}{c}\text { EpApp } \\
\text { (Sidney Children's Hospitals Network) }\end{array}$ & 1 & 4.4 & 3.2 & 4.0 & 4.5 & 4.2 \\
\hline $\begin{array}{l}\text { Epi \& Me } \\
\text { (HandMe) }\end{array}$ & 3 & 3.3 & 4.0 & 3.9 & 3.8 & 3.8 \\
\hline $\begin{array}{l}\text { EpiCalendar } \\
\text { (MedyCal) }\end{array}$ & 3 & 2.3 & 3.9 & 2.6 & 2.5 & 2.6 \\
\hline $\begin{array}{l}\text { EpiDiary } \\
\text { (Irody Inc.) }\end{array}$ & 2 & 3.5 & 3.4 & 3.0 & 3.4 & 3.4 \\
\hline $\begin{array}{c}\text { Epilepsia } \\
\text { (Maleny Abrego) }\end{array}$ & 3 & 3.0 & 3.2 & 2.7 & 2.3 & 2.8 \\
\hline $\begin{array}{l}\text { Epilepsy Seizures Diary } \\
\text { (MedTests) }\end{array}$ & 2 & 1.3 & 3.4 & 3.2 & 2.8 & 3.2 \\
\hline $\begin{array}{l}\text { Epilepsy Connect } \\
\text { (Epilepsy France) }\end{array}$ & 3 & 3.9 & 4.0 & 4.1 & 3.8 & 4.0 \\
\hline $\begin{array}{l}\text { Epilepsy Ireland } \\
\text { (Epilepsy Ireland) }\end{array}$ & 3 & 3.2 & 3.7 & 3.0 & 3.2 & 3.2 \\
\hline $\begin{array}{c}\text { Epilepsy Journal } \\
\text { (Olly Tree Applications) }\end{array}$ & 6 & 4.3 & 4.4 & 4.1 & 4.0 & 4.2 \\
\hline $\begin{array}{l}\text { GSK MI Epilepsia } \\
\text { (Pharmaconsult, SA) }\end{array}$ & 3 & 3.8 & 4.3 & 4.0 & 4.1 & 4.0 \\
\hline $\begin{array}{l}\text { Helpilepsy } \\
\text { (Epione BVBA) }\end{array}$ & 6 & 4.2 & 4.5 & 4.7 & 3.9 & 4.4 \\
\hline $\begin{array}{l}\text { Kairy Epilepsy } \\
\text { (Kairy Limited) }\end{array}$ & 3 & 3.2 & 4.1 & 3.7 & 3.8 & 3.8 \\
\hline $\begin{array}{l}\text { My Epilepsy } \\
\text { ( Foundation) }\end{array}$ & 2 & 2.2 & 3.6 & 2.2 & 2.8 & 2.5 \\
\hline $\begin{array}{c}\text { My Seizure Diary } \\
\text { (Epilepsy Foundation) }\end{array}$ & 2 & 3.8 & 2.6 & 3.2 & 2.8 & 3.0 \\
\hline $\begin{array}{c}\text { myChildren's } \\
\text { (Nationwide Children's Hospital) }\end{array}$ & 3 & 3.6 & 3.5 & 3.1 & 3.8 & 3.6 \\
\hline $\begin{array}{l}\text { PurpleCare } \\
\text { (DHYGEE SA) }\end{array}$ & 6 & 4.1 & 4.4 & 4.4 & 4.0 & 4.2 \\
\hline
\end{tabular}


Table A4. Cont.

\begin{tabular}{ccccccc}
\hline Name & N Raters & Engagement & Functionality & Aesthetics & Information & Overall \\
\hline $\begin{array}{c}\text { SeizAlarm } \\
\text { (SeizAlarm LLC) }\end{array}$ & 2 & 3.5 & 4.2 & 3.7 & 4.0 & 3.8 \\
\hline $\begin{array}{c}\text { Epipal (Seizario) } \\
\text { (HealthAppy Tech) }\end{array}$ & 2 & 2.8 & 3.4 & 3.0 & 2.1 & 3.9 \\
\hline $\begin{array}{c}\text { Seizure Tracker/ Seizure Log } \\
\text { (Seizure Tracker LLC) }\end{array}$ & 6 & 2.7 & 3.8 & 3.3 & 3.6 & 3.1 \\
\hline $\begin{array}{c}\text { Simple Seizure Diary } \\
\text { (Luke Berry) }\end{array}$ & 2 & 4.1 & 4.2 & 3.6 & 3.9 \\
\hline $\begin{array}{c}\text { Social-SERAS Epilepsy } \\
\text { (mjn-neuro) }\end{array}$ & 3 & 3.2 & 3.7 & 3.1 & 3.1 \\
\hline $\begin{array}{c}\text { SOENIA Medical Diary } \\
\text { (BrainCare Oy) }\end{array}$ & 3 & 3.1 & 4.1 & 3.3 \\
\hline
\end{tabular}

\section{References}

1. World Health Organization, Global Campaign against Epilepsy, Programme for Neurological Diseases, Neuroscience (World Health Organization), International Bureau for Epilepsy, World Health Organization; Department of Mental Health, Substance Abuse, International Bureau of Epilepsy and International League against Epilepsy. Atlas: Epilepsy Care in the World; World Health Organization: Geneva, Switzerland, 2005.

2. French, J.A. Refractory epilepsy: Clinical overview. Epilepsia 2007, 48, 3-7. [CrossRef]

3. Beghi, E. Addressing the burden of epilepsy: Many unmet needs. Pharmacol. Res. 2016, 107, 79-84. [CrossRef]

4. Assenza, G.; Lanzone, J.; Brigo, F.; Coppola, A.; Di Gennaro, G.; Di Lazzaro, V.; Ricci, L.; Romigi, A.; Tombini, M.; Mecarelli, O. Epilepsy care in the time of COVID-19 pandemic in Italy: Risk factors for seizure worsening. Front. Neurol. 2020, $11,737$. [CrossRef]

5. Moalong, K.M.C.; Espiritu, A.I.; Fernandez, M.L.L.; Jamora, R.D.G. Treatment gaps and challenges in epilepsy care in the Philippines. Epilepsy Behav. 2021, 115, 107491. [CrossRef] [PubMed]

6. Mahendran, M.; Speechley, K.N.; Widjaja, E. Systematic review of unmet healthcare needs in patients with epilepsy. Epilepsy Behav. 2017, 75, 102-109. [CrossRef] [PubMed]

7. Fesler, J.R.; Stanton, S.; Merner, K.; Ross, L.; McGinley, M.P.; Bena, J.; Rasmussen, P.; Najm, I.; Punia, V. Bridging the gap in epilepsy care: A single-center experience of 3700 outpatient tele-epilepsy visits. Epilepsia 2020, 61, e95-e100. [CrossRef] [PubMed]

8. Fisher, R.S.; Blum, D.E.; DiVentura, B.; Vannest, J.; Hixson, J.D.; Moss, R.; Herman, S.T.; Fureman, B.E.; French, J.A. Seizure diaries for clinical research and practice: Limitations and future prospects. Epilepsy Behav. 2012, 24, 304-310. [CrossRef] [PubMed]

9. Bandura, A. Self-efficacy: Toward a unifying theory of behavioral change. Psychol. Rev. 1977, 84, 191. [CrossRef]

10. Dilorio, C.; Henry, M. Self-management in persons with epilepsy. J. Neurosci. Nurs. J. Am. Assoc. Neurosci. Nurses 1995, 27, 338-343. [CrossRef]

11. Fraser, R.T.; Johnson, E.K.; Lashley, S.; Barber, J.; Chaytor, N.; Miller, J.W.; Ciechanowski, P.; Temkin, N.; Caylor, L. PACES in epilepsy: Results of a self-management randomized controlled trial. Epilepsia 2015, 56, 1264-1274. [CrossRef]

12. Blachut, B.; Hoppe, C.; Surges, R.; Elger, C.; Helmstaedter, C. Subjective seizure counts by epilepsy clinical drug trial participants are not reliable. Epilepsy Behav. 2017, 67, 122-127. [CrossRef] [PubMed]

13. Patel, J.; Feng, W.; Chen, K.; French, J.A.; Rushton, M.; Hubbard, S.; Ren, Z.; Potero, E.; Parkerson, K.A. Use of an electronic seizure diary in a randomized, controlled trial of natalizumab in adult participants with drug-resistant focal epilepsy. Epilepsy Behav. 2021, 118, 107925. [CrossRef] [PubMed]

14. Conde-Blanco, E.; Centeno, M.; Tio, E.; Muriana, D.; García-Peñas, J.J.; Serrano, P.; Nagel, A.G.; Serratosa, J.; Jiménez, Á.P.; Toledo, M.; et al. Emergency implementation of telemedicine for epilepsy in Spain: Results of a survey during SARS-CoV-2 pandemic. Epilepsy Behav. 2020, 111, 107211. [CrossRef] [PubMed]

15. Escoffery, C.; McGee, R.; Bidwell, J.; Sims, C.; Thropp, E.K.; Frazier, C.; Mynatt, E.D. A review of mobile apps for epilepsy self-management. Epilepsy Behav. 2018, 81, 62-69. [CrossRef] [PubMed]

16. Zoellner, J.P.; Wolking, S.; Weber, Y.; Rosenow, F. Decision-support-Systeme, Assistenzsysteme und Telemedizin in der Epileptologie. Der Nervenarzt 2021, 92, 95-106. [CrossRef] [PubMed]

17. Mohammadzadeh, N.; Khenarinezhad, S.; Ghazanfarisavadkoohi, E.; Safari, M.S.; Pahlevanynejad, S. Evaluation of M-Health Applications Use in Epilepsy: A Systematic Review. Iran. J. Public Health 2021, 50, 459-469. [CrossRef]

18. Phongtraychack, A.; Dolgaya, D. Evolution of Mobile Applications. MATEC Web Conf. 2018, 155, 01027. [CrossRef] 
19. Statista Research Department. Average Number of New Android App Releases via Google Play per Month from March 2019 to November 2021. 2021. Available online: https:/ /www.statista.com/statistics/1020956/android-app-releases-worldwide/ (accessed on 1 January 2022).

20. 42Matters. iOS Apple App Store Statistics and Trends 2021. 2021. Available online: https://42matters.com/ios-apple-app-storestatistics-and-trends (accessed on 1 January 2022).

21. Shamseer, L.; Moher, D.; Clarke, M.; Ghersi, D.; Liberati, A.; Petticrew, M.; Shekelle, P.; Stewart, L.A. Preferred reporting items for systematic review and meta-analysis protocols (PRISMA-P) 2015: Elaboration and explanation. BMJ 2015, 349, 7-9. [CrossRef]

22. Grady, P.A.; Gough, L.L. Self-management: A comprehensive approach to management of chronic conditions. Am. J. Public Health 2014, 104, e25-e31. [CrossRef]

23. Stoyanov, S.R.; Hides, L.; Kavanagh, D.J.; Zelenko, O.; Tjondronegoro, D.; Mani, M. Mobile App Rating Scale: A New Tool for Assessing the Quality of Health Mobile Apps. JMIR mHealth uHealth 2015, 3, e27. [CrossRef]

24. Knitza, J.; Tascilar, K.; Messner, E.M.; Meyer, M.; Vossen, D.; Pulla, A.; Bosch, P.; Kittler, J.; Kleyer, A.; Sewerin, P.; et al. German mobile apps in rheumatology: Review and analysis using the Mobile Application Rating Scale (MARS). JMIR $m$ Health $u$ Health 2019, 7, e14991. [CrossRef] [PubMed]

25. Goldenholz, D.M.; Moss, R.; Scott, J.; Auh, S.; Theodore, W.H. Confusing placebo effect with natural history in epilepsy: A big data approach. Ann. Neurol. 2015, 78, 329-336. [CrossRef]

26. Chiang, S.; Moss, R.; Patel, A.D.; Rao, V.R. Seizure detection devices and health-related quality of life: A patient-and caregivercentered evaluation. Epilepsy Behav. 2020, 105, 106963. [CrossRef] [PubMed]

27. Chiang, S.; Goldenholz, D.M.; Moss, R.; Rao, V.R.; Haneef, Z.; Theodore, W.H.; Kleen, J.K.; Gavvala, J.; Vannucci, M.; Stern, J.M. Prospective validation study of an epilepsy seizure risk system for outpatient evaluation. Epilepsia 2020, 61, 29-38. [CrossRef] [PubMed]

28. Helmy, A.; Helmy, A. Seizario: Novel Mobile Algorithms for Seizure and Fall Detection. In Proceedings of the 2015 IEEE Globecom Workshops (GC Wkshps), San Diego, CA, USA, 6-10 December 2015; pp. 1-6.

29. Helmy, A.; Helmy, A. Detecting epileptic seizures with a smartphone using frequency analysis. In Proceedings of the IEEE INFOCOM 2018-IEEE Conference on Computer Communications Workshops (INFOCOM WKSHPS), Honolulu, HI, USA, 15-19 April 2018; pp. 1-2.

30. SOENIA. Clinical Evidence-SOENIA. Available online: https://gettingbetter.fi/testi/wordpress/clinical-evidence/ (accessed on 23 September 2021).

31. Dhygee. Dhygee-The Patient Dedicated Digital Healthcare Start-Up. Available online: https://dhygee.com/\#our-awards (accessed on 23 September 2021).

32. Brigo, F.; Bonavita, S.; Leocani, L.; Tedeschi, G.; Lavorgna, L. Telemedicine and the challenge of epilepsy management at the time of COVID-19 pandemic. Epilepsy Behav. 2020, 110, 107164. [CrossRef] [PubMed]

33. Helpilepsy. Patient-Helpilepsy. Available online: https://helpilepsy.com/patient/ (accessed on 23 September 2021).

34. Foundation, D.S. MemberMonday Spotlight. Available online: https://www.dravetfoundation.org/member-monday-davidand-natasha / ?eType=EmailBlastContent\&eId=56ace3cb-995e-4ef3-a3d8-43c787b78fda (accessed on 23 September 2021).

35. Le Marne, F.A.; Butler, S.; Beavis, E.; Gill, D.; Bye, A.M. EpApp: Development and evaluation of a smartphone/tablet app for adolescents with epilepsy. J. Clin. Neurosci. 2018, 50, 214-220. [CrossRef]

36. Yoo, S.; Lim, K.; Baek, H.; Jang, S.K.; Hwang, G.Y.; Kim, H.; Hwang, H. Developing a mobile epilepsy management application integrated with an electronic health record for effective seizure management. Int. J. Med. Inform. 2020, 134, 104051. [CrossRef]

37. Choi, S.A.; Lim, K.; Baek, H.; Yoo, S.; Cho, A.; Kim, H.; Hwang, H.; Kim, K.J. Impact of mobile health application on data collection and self-management of epilepsy. Epilepsy Behav. 2021, 119, 107982. [CrossRef]

38. Alzamanan, M.Z.; Lim, K.S.; Ismail, M.A.; Ghani, N.A. Self-Management Apps for People With Epilepsy: Systematic Analysis. JMIR mHealth uHealth 2021, 9, e22489. [CrossRef]

39. Dozières-Puyravel, B.; Danse, M.; Goujon, E.; Höhn, S.; Auvin, S. Views of adolescents and their parents on mobile apps for epilepsy self-management. Epilepsy Behav. 2020, 106, 107039. [CrossRef]

40. Thompson, M.E.; Goodwin, R.; Ojeda, A.; Morris, L.; Fairman, A.D. User preferences for the design of a mobile health system to support transition-age youth with epilepsy. J. Pediatr. Health Care 2020, 34, e28-e36. [CrossRef] [PubMed]

41. Rahim, M.I.A.; Thomas, R.H. Gamification of medication adherence in epilepsy. Seizure 2017, 52, 11-14. [CrossRef]

42. Stirling, R.E.; Cook, M.J.; Grayden, D.B.; Karoly, P.J. Seizure forecasting and cyclic control of seizures. Epilepsia 2021, 62, S2-S14. [CrossRef]

43. Payne, D.E.; Dell, K.L.; Karoly, P.J.; Kremen, V.; Gerla, V.; Kuhlmann, L.; Worrell, G.A.; Cook, M.J.; Grayden, D.B.; Freestone, D.R Identifying seizure risk factors: A comparison of sleep, weather, and temporal features using a Bayesian forecast. Epilepsia 2021, 62, 371-382. [CrossRef] [PubMed]

44. Schnall, R.; Rojas, M.; Bakken, S.; Brown, W.; Carballo-Dieguez, A.; Carry, M.; Gelaude, D.; Mosley, J.P.; Travers, J. A user-centered model for designing consumer mobile health (mHealth) applications (apps). J. Biomed. Inform. 2016, 60, 243-251. [CrossRef]

45. Goldenholz, D.M.; Moss, R.; Jost, D.A.; Crone, N.E.; Krauss, G.; Picard, R.; Caborni, C.; Cavazos, J.E.; Hixson, J.; Loddenkemper, T.; et al. Common data elements for epilepsy mobile health systems. Epilepsia 2018, 59, 1020-1026. [CrossRef] 